Check for updates

Cite this: J. Mater. Chem. A, 2021, 9, 18927

Received 1st April 2021

Accepted 1st June 2021

DOI: $10.1039 / \mathrm{d} 1 \mathrm{ta} 02741 \mathrm{~g}$

rsc.li/materials-a

\section{Modulating the electronic structure of nanomaterials to enhance polysulfides confinement for advanced lithium-sulfur batteries}

\author{
Shuang Zhao, (D) Yajuan Kang, Minjie Liu, Bihan Wen, Qi Fang, Yaoyao Tang,
} Shicheng $\mathrm{He}$, Xin Ma, ${ }^{*}$ Mingkai Liu (D) ${ }^{*}$ and Yan Yan (D)*

Lithium-sulfur (Li-S) battery is one of the most promising next-generation energy storage systems. Nevertheless, owing to the high solubility of lithium polysulfides (LiPSs) in the ether-based electrolyte, plenty of LiPSs shuttle between cathode and anode under an electric field. This shuttle effect corrodes the lithium metal, and thus causes serious capacity fading, which is regarded as a major barrier to the commercial application of $\mathrm{Li}-\mathrm{S}$ batteries. Engineering the surficial structure of nanomaterials can promote affinity between cathode and LiPSs, while simultaneously facilitating redox kinetics of LiPSs, leading to a low concentration of LiPSs in electrolyte for restraining the shuttle effect. Herein, we review recent progress in manipulating the electronic structure of nanomaterials featuring high conductivity, strong absorption and catalytic properties for $\mathrm{Li}-\mathrm{S}$ batteries. We first discuss the mechanism of the conversion of LiPSs with different pathways. Moreover, we showcase the design strategies of nanomaterials with the modulated surface, including heterostructures, deficiency strategy, heteroatomdoping strategy and metal-single-atom catalyst. Future perspectives and challenges are also proposed for constructing stable Li-S batteries with high energy density.

\section{Introduction}

Amid increasingly severe environmental concerns, electrochemical energy storage systems have greatly progressed. Among numerous candidates in the next-generation energy storage arena, the lithium-sulfur ( $\mathrm{Li}-\mathrm{S})$ battery has emerged as particularly promising, which embraces high theoretical energy density $\left(\approx 2600 \mathrm{Wh} \mathrm{kg}^{-1}\right)$, low cost and environmental friendliness. ${ }^{1,2}$ Despite these advantages, the commercialization of Li-S batteries depends on simultaneously solving many
School of Chemistry \& Materials Science, Jiangsu Key Laboratory of Green Synthetic Chemistry for Functional Materials, Jiangsu Normal University, 221116 Xuzhou, P.
R. China. E-mail: yanyan@jsnu.edu.cn; liumingkai@jsnu.edu.cn; xmanager12356a@163.com

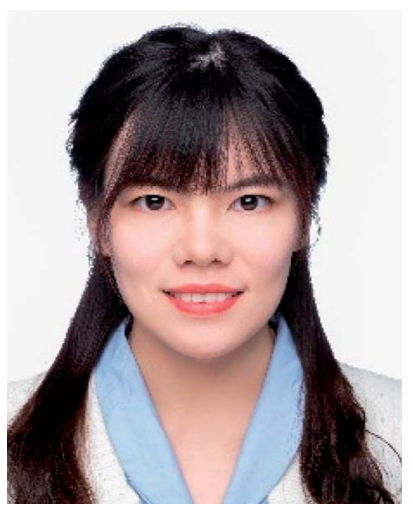

Shuang Zhao is an associate professor in School of Chemistry and Materials Science at Jiangsu Normal University. She earned her $P h D$ in Environmental Science and Engineering from Shandong University in 2016. Her research interests focus on water pollution control technology, water treatment agent, nanocarbon materials and lithium-sulfur batteries.

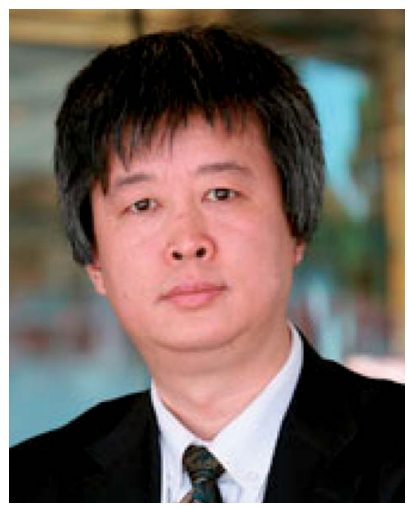

Xin Ma is a professor in School of Chemistry and Materials Science at Jiangsu Normal University. He earned his BS degree in Physics Electronics at Zhejiang University, and he received his Master degree in Physics Electronics and later his $\mathrm{PhD}$ in Electrical Engineering at Institute of Electronics, Chinese Academy of Sciences in 2000. He studied at Tsinghua University as a post doc. from 2000-2003. Then he worked in research labs in industry until return to Jiangsu Normal University. His research interests focus on anode material and high energy density solid state Li-ion battery. 
underlying problems. During charge and discharge processes, the volume change of sulfur (sulfur/lithium sulfide) is up to $80 \%$, leading to a structural collapse and pulverization of the sulfur cathode. ${ }^{3,4}$ More importantly, the poor conductivity of sulfur together with the shuttle effect of soluble lithium polysulfides (LiPSs), resulting in an unsatisfied active-sulfur utilization and poor cycling stability. ${ }^{5-7}$ In addition, due to the diffusion of LiPSs, undissolved $\mathrm{Li}_{2} \mathrm{~S}_{2} / \mathrm{Li}_{2} \mathrm{~S}$ are inhomogeneously deposited on the anode surface, which causes the passivation of the anode and low coulombic efficiency. ${ }^{\mathbf{8}, 9}$ Consequently, the shuttle effect of LiPSs is regarded as one of the critical points impeding the application of $\mathrm{Li}-\mathrm{S}$ batteries. ${ }^{10,11}$

Recently, considerable efforts have been devoted to hinder LiPSs shuttling by means of increasing the affinity between electrode and LiPSs (i.e., physical blocking, chemical adsorption) and accelerating the LiPS conversion kinetics. ${ }^{12-14}$ Owing to the high conductivity and large surface area, various carbon materials (i.e., graphene, carbon nanotube (CNT), carbon nanofiber (CNF), porous carbon materials) have been employed as the sulfur host in Li-S batteries. ${ }^{15-18}$ Furthermore, heteroatoms (i.e., B, N, P, S) are introduced into the surface of carbon materials, which can produce strong chemical affinity, and then suppress the diffusion of LiPSs more efficiently. ${ }^{19-21}$ In addition, due to the high activation energy, the conversion from soluble LiPSs to insoluble $\mathrm{Li}_{2} \mathrm{~S}_{2} / \mathrm{Li}_{2} \mathrm{~S}$ in electrode/electrolyte interface is sluggish, which will aggravate the diffusion of LiPSs from cathode to anode. ${ }^{22,23}$ Hence, accelerating the sulfur redox reaction has recently emerged as a new frontier of research, and many catalysts, such as transition-metal oxides, sulfides, nitrides, were employed as sulfur hosts in Li-S batteries. ${ }^{24-27}$ These catalysts could facilitate long-chain LiPSs $\left(\mathrm{Li}_{2} \mathrm{~S}_{8}, \mathrm{Li}_{2} \mathrm{~S}_{6}\right.$, $\mathrm{Li}_{2} \mathrm{~S}_{4}$ ) reduced to short-chain $\mathrm{Li}_{2} \mathrm{~S}_{2} / \mathrm{Li}_{2} \mathrm{~S}$ via lowing energy barriers or changing the sulfur redox pathways. ${ }^{28,29}$ Moreover, catalysts also can produce abundant polar active sites on the cathode surface, which will aggregate LiPSs with high concentration at the electrochemical interface, leading to speeding up

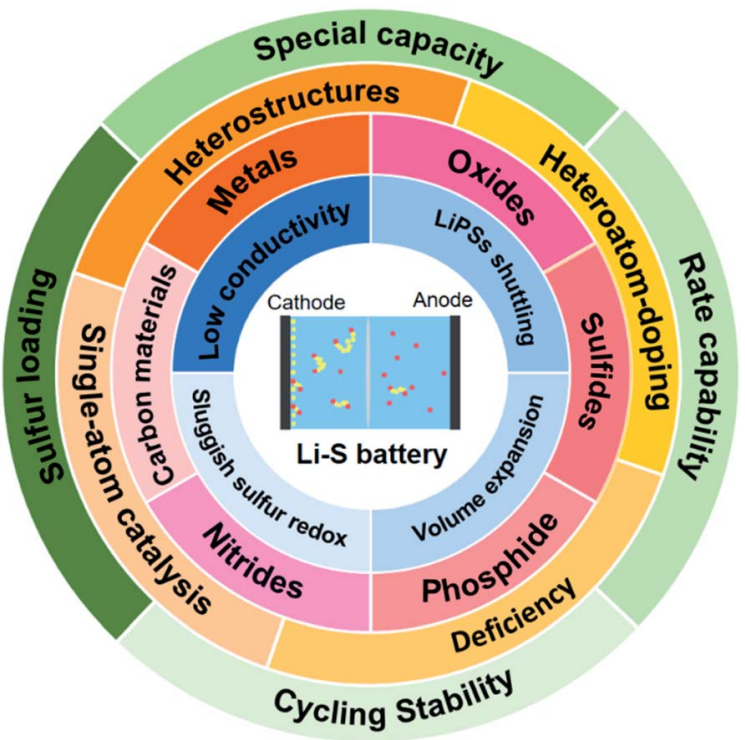

Fig. 1 Schematic of the uses of surface engineering strategy to address the key challenges on Li-S batteries.

the reaction and enhance the reaction kinetics. ${ }^{27,30}$ Taken together, the synergistic effect of adsorption and catalysis of nanomaterials have opened a new gate to finally alleviate LiPSs shuttling.

The ability of adsorption and catalysis with LiPSs is largely determined by the local electronic structure of nanomaterials. $^{31,32}$ It is notable that recently advanced cathode materials were constructed via surface engineering strategies to enhance the adsorption ability of the polysulfides and promote their conversion kinetics, and thus achieve high-performance Li-S batteries (Fig. 1). The aim of this review is to bring together the mechanism of polysulfides conversion and recent advanced strategies for surficial electronic structure modulation of nanomaterials, including forming heterostructure,

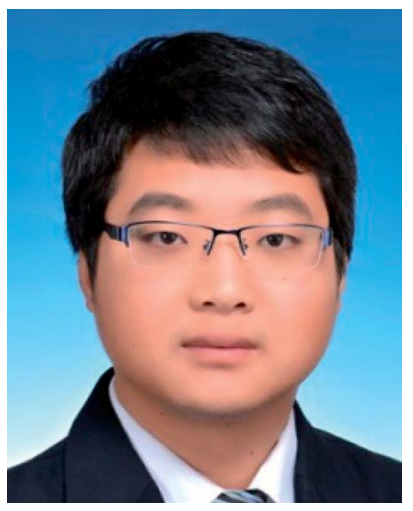

Mingkai Liu received his $B S$ degree from the School of Chemistry and Chemical Engineering, Henan University in 2008, and then received his M.S. degree in Chemical Engineering from Guangdong University of Technology in 2011 and PhD degree in Macromolecular Science from Fudan University in 2014. He joined Younan Xia's group as a postdoc in Georgia Institute of Technology from 2018-2020. Now, he is an associate professor at Jiangsu Normal University. His research interests include the development of functional nanomaterials for applications in catalysis, energy storage/conversion and environmental science.

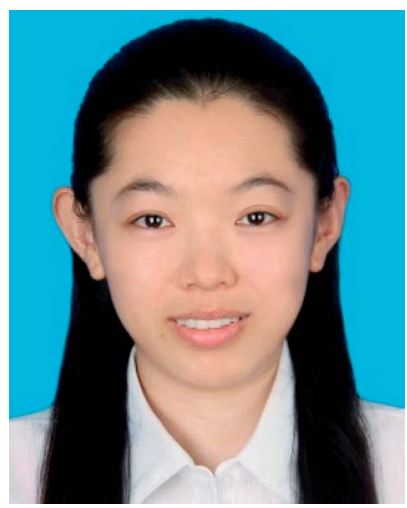

Yan Yan is an associate professor in School of Chemistry and Materials Science at Jiangsu Normal University. She earned her BS degree in Materials Chemistry at Henan University, and later received her $P h D$ in Inorganic Chemistry from Sun Yat-Sen University in 2014. She studied at the Georgia Institute of Technology as a visiting scholar from 2019-2020. Her research interests focus on nanocarbon materials, advanced energy storage/conversion, lithium-sulfur batteries, and catalysis. 


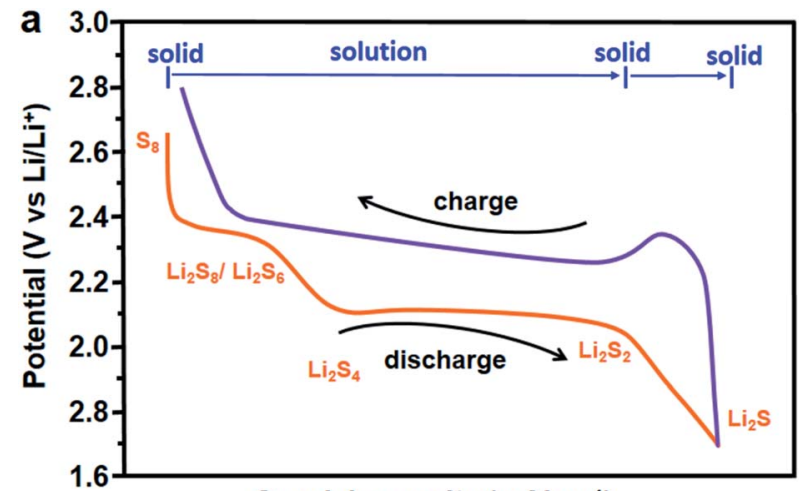

Special capacity $\left(\mathrm{mAh} \mathrm{g}^{-1}\right)$

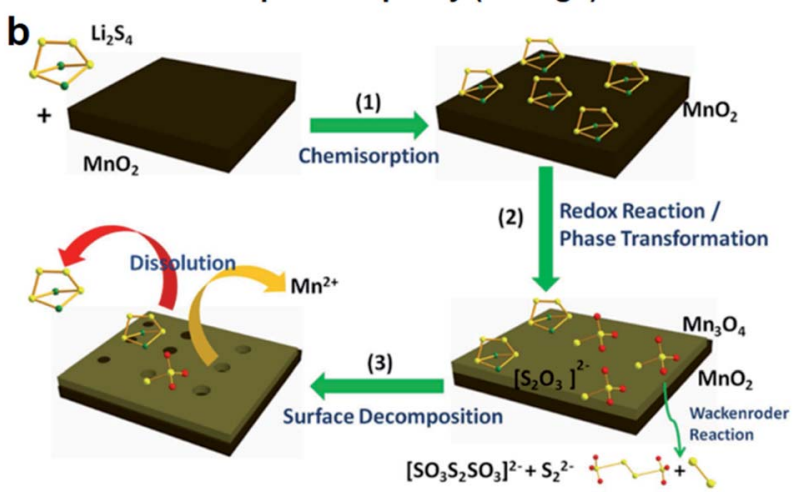

Fig. 2 (a) A typical charge/discharge profile for a Li-S battery. (b) Schematic illustration of the proposed interaction mechanisms of polysulfide and $\gamma-\mathrm{MnO}_{2}$ on the surface. Reproduced with permission. ${ }^{29}$ Copyright 2017, Wiley-VCH.

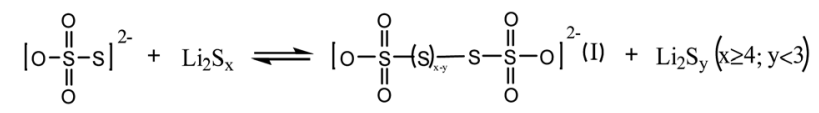

Scheme 1 The reactions of thiosulfate and LiPSs.

constructing surface defects, introducing heteroatoms and decorating single metal atoms.

\section{The mechanism of sulfur redox reaction for $\mathrm{Li}-\mathrm{S}$ battery}

A typical Li-S battery undergoes an overall discharge reaction of $16 \mathrm{Li}+\mathrm{S}_{8} \rightarrow 8 \mathrm{Li}_{2} \mathrm{~S}$, which generates a series of intermediate polysulfides $\left(\mathrm{Li}_{2} \mathrm{~S}_{x}, 2 \leq x \leq 8\right)$, including soluble long-chain polysulfides $\left(\mathrm{Li}_{2} \mathrm{~S}_{x},(4 \leq x \leq 8)\right)$ and insoluble short-chain $\mathrm{Li}_{2} \mathrm{~S}_{2}$ and $\mathrm{Li}_{2} \mathrm{~S} .^{33}$ In this process, the conversion reactions among these intermediates are complex with the considerations of complicated reaction pathways of different kinetics combined with twice-phase transformation (solid/liquid/ solid). ${ }^{34}$ Hence, various efforts have been dedicated to illuminating the reaction mechanism of $\mathrm{Li}-\mathrm{S}$ batteries from both experiments and theoretical models. Up to now, a simplified reaction sequence of $\mathrm{S}_{8} \rightarrow \mathrm{Li}_{2} \mathrm{~S}_{8} \rightarrow \mathrm{Li}_{2} \mathrm{~S}_{6} / \mathrm{Li}_{2} \mathrm{~S}_{4} \rightarrow \mathrm{Li}_{2} \mathrm{~S}_{2} / \mathrm{Li}_{2} \mathrm{~S}$ has been considered as a widely accepted illustration of the reaction process of Li-S batteries, while other polysulfide intermediates through disproportionation/decomposition reaction have also been discovered. ${ }^{35}$

\section{Polysulfide redox pathway}

Sulfur, which supplies more than 30 solid allotropes, always exhibits in the most stable form of cyclic octasulfur $\left(\mathrm{S}_{8}\right) \cdot{ }^{36}$ In the Li-S battery, a typical charge/discharge profile is shown in Fig. 2a. It can be seen that $S_{8}$ undergoes compositional and structural changes during the redox process, which covers a solid $\left(\mathrm{S}_{8}\right) \rightarrow$ liquid $\left(\mathrm{Li}_{2} \mathrm{~S}_{8}, \mathrm{Li}_{2} \mathrm{~S}_{6}, \mathrm{Li}_{2} \mathrm{~S}_{4}\right) \rightarrow$ solid $\left(\mathrm{Li}_{2} \mathrm{~S}_{2} / \mathrm{Li}_{2} \mathrm{~S}\right)$ phase transformation with a gradual decrease in the sulfur chain length. ${ }^{37}$ With the battery potential decreasing and special capacity increasing, the electrochemical reactions of Li$\mathrm{S}$ batteries are as follows:

$$
\begin{gathered}
\mathrm{S}_{8}+2 \mathrm{e}^{-}+2 \mathrm{Li}^{+} \rightarrow \mathrm{Li}_{2} \mathrm{~S}_{8} \\
3 \mathrm{Li}_{2} \mathrm{~S}_{8}+2 \mathrm{e}^{-}+2 \mathrm{Li}^{+} \rightarrow 4 \mathrm{Li}_{2} \mathrm{~S}_{6} \\
2 \mathrm{Li}_{2} \mathrm{~S}_{6}+2 \mathrm{e}^{-}+2 \mathrm{Li}^{+} \rightarrow 3 \mathrm{Li}_{2} \mathrm{~S}_{4} \\
\mathrm{Li}_{2} \mathrm{~S}_{4}+2 \mathrm{e}^{-}+2 \mathrm{Li}^{+} \rightarrow 2 \mathrm{Li}_{2} \mathrm{~S}_{2} \\
\mathrm{Li}_{2} \mathrm{~S}_{2}+2 \mathrm{e}^{-}+2 \mathrm{Li}^{+} \rightarrow 2 \mathrm{Li}_{2} \mathrm{~S}
\end{gathered}
$$

Solid $\mathrm{S}_{8}$ is reduced to soluble $\mathrm{Li}_{2} \mathrm{~S}_{8}$ and $\mathrm{Li}_{2} \mathrm{~S}_{6}$, and subsequently to $\mathrm{Li}_{2} \mathrm{~S}_{4}$ at the potential of $2.3-2.1 \mathrm{~V}\left(v s\right.$. $\left.\mathrm{Li}^{-} / \mathrm{Li}^{+}\right)$, corresponding to a theoretical capacity of $418 \mathrm{~mA} \mathrm{~h} \mathrm{~g}{ }^{-1}$ with 0.5 electron transfer per $\mathrm{S}$ atom. Subsequently, soluble $\mathrm{Li}_{2} \mathrm{~S}_{4}$ is further reduced to insoluble $\mathrm{Li}_{2} \mathrm{~S}_{2}$ at the potential of 2.1-1.9 V (vs. $\mathrm{Li} / \mathrm{Li}^{+}$), which corresponds to 0.5 electron transfer per $\mathrm{S}$ atom, leading to the theoretical capacity of $1254 \mathrm{~mA} \mathrm{~h} \mathrm{~g}^{-1}$. Finally, insoluble $\mathrm{Li}_{2} \mathrm{~S}_{2}$ aggregates on the electrode surface and causes further reduction of $\mathrm{Li}_{2} \mathrm{~S}$. In the above conversion process, the high solubility of these long-chain lithium polysulfides shows fast reaction kinetics. Nonetheless, due to the conversion reaction between solid $\mathrm{Li}_{2} \mathrm{~S}_{2}$ and $\mathrm{Li}_{2} \mathrm{~S}$, the reaction kinetics are much slower than the conversion of soluble polysulfides. During the subsequent charging process, $\mathrm{Li}_{2} \mathrm{~S}$ reconverts to sulfur through the formation of intermediate LiPSs, resulting in a reversible cycle. Besides, the reaction routes of polysulfide conversion with the formation of $\mathrm{Li}_{2} \mathrm{~S}_{7}, \mathrm{Li}_{2} \mathrm{~S}_{5}$ and $\mathrm{Li}_{2} \mathrm{~S}_{3}$ are also determined, but the regulation and mechanism of electrode materials on the component and structure of polysulfide intermediates deserve further investigation. ${ }^{38,39}$

\section{Thiosulfate redox pathway}

Recently, some studies have clarified that part of sulfur hosts can oxidize polysulfides to thiosulfate (or sulfate), such as transition metal oxides (i.e., $\mathrm{MnO}_{2}, \mathrm{CuO}$ ), which have a redox potential above $2.4 \mathrm{~V}$ based on the "Goldilocks" principle. ${ }^{40}$ Recent research studies suggest that sulfides, nitrides and carbon-based materials could also generate thiosulfate during the discharge process of Li-S batteries (Scheme 1). ${ }^{41-43}$ The electrochemical reactions of thiosulfate and LiPSs (reaction (6)) are as follows: 
Table 1 Electrochemical properties of Li-S batteries with heterostructured materials

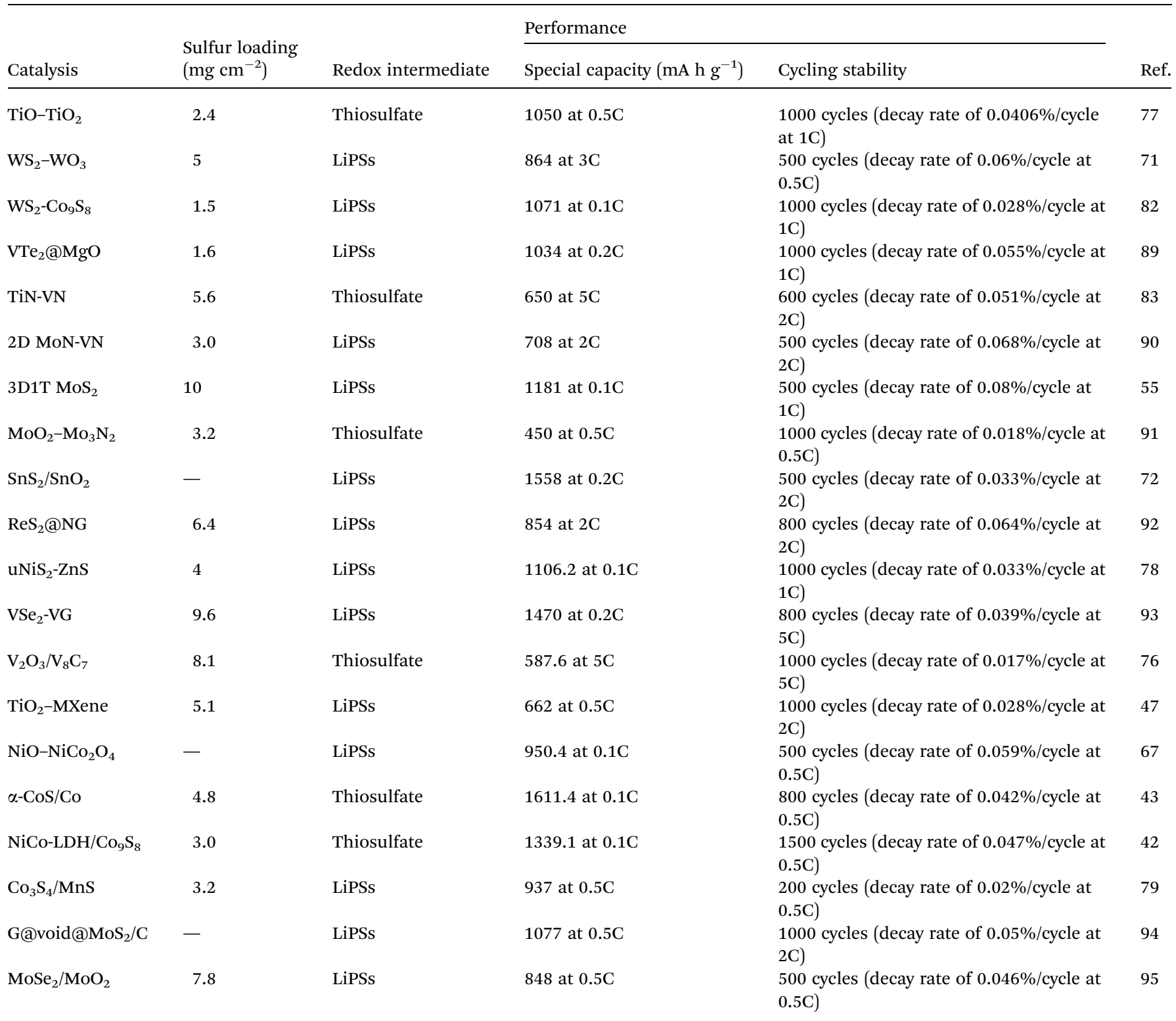

Especially, it has been reported that $\gamma-\mathrm{MnO}_{2}$ has catalytic power in the conversion of polysulfides through thiosulfate. ${ }^{29}$ The redox interaction between polysulfides and the $\gamma-\mathrm{MnO}_{2}$ host is shown in Fig. 2b. First, the soluble LiPSs are adsorbed on the surface of $\gamma-\mathrm{MnO}_{2}$, due to the strong polar active site of the $\mathrm{Mn}$ atom. Subsequently, LiPSs are oxidised to $\mathrm{SO}_{x}$ species via the transfer of oxygen atoms from $\gamma-\mathrm{MnO}_{2}$ surface to LiPS molecules, coupled with the phase transformation from $\gamma$ $\mathrm{MnO}_{2}$ to $\mathrm{Mn}_{3} \mathrm{O}_{4}$. Then, polysulfides catenate to the thiosulfate by inserting into the S-S single bond to create a polythionate complex (I) and short-chain polysulfide (i.e., $\mathrm{Li}_{2} \mathrm{~S}_{2}$ or $\mathrm{Li}_{2} \mathrm{~S}$ ) (reaction (6)) through an internal disproportionation reaction. Compared with the traditional LiPSs redox pathway $\left(\mathrm{S}_{8} \rightarrow \mathrm{Li}_{2} \mathrm{~S}_{8}\right.$, $\mathrm{Li}_{2} \mathrm{~S}_{6}, \mathrm{Li}_{2} \mathrm{~S}_{4} \rightarrow \mathrm{Li}_{2} \mathrm{~S}_{2} / \mathrm{Li}_{2} \mathrm{~S}$ ), the polysulfides conversion process with thiosulfate always couples with the redox reaction of the sulfur host. Thus, it is dedicated to being a promising way to realize a long-life Li-S battery by optimizing the structure of materials for modulating redox potentials and facilitating contact with LiPSs.

\section{Strategies for surficial electronic structure modulation}

\section{Heterostructures}

Heterostructure refers to the composites formed by two or more chemically bonded solid materials. ${ }^{44,45}$ Due to the synergistic effects of each component/element, materials with heterostructure exhibit effective LiPSs adsorption/catalytic conversion (at the cathode) and uniform Li nucleation/growth (at the anode) properties, which provide an effective strategy to figure 
out the long-standing inherent problems of lithium-sulfur batteries, such as poor conductivity, sluggish redox kinetics, poor cycling ability. ${ }^{4-48}$ Consequently, based on the reasonable selection of solid materials with favorable synergistic effects, the heterogeneous structure could be prepared with perfect physical and chemical properties to satisfy the stringent requirements for a high-performance $\mathrm{Li}-\mathrm{S}$ battery. ${ }^{49}$ According to recent research studies, potentially functional heterostructures for cathode host can be categorized as carbon-based heterostructures, metal compound-based heterostructures, and polymer-based heterostructures. Table 1 shows the electrochemical properties of $\mathrm{Li}-\mathrm{S}$ batteries with heterostructures.

3.1 Carbon-based heterostructures. In previous studies, carbon materials have become one of the most widely used substrates for heterostructures construction due to their excellent electrical conductivity, large specific surface area and favorable mechanical stability. ${ }^{50}$ In this review, carbon-based heterostructures mainly refer to hybrid materials, which combine metal compounds (i.e., metal oxides, sulfides, nitrides, phosphide) with conductive carbonaceous materials (i.e., graphene, CNT, CNF, etc.). This direct combination supplies a large surface area to accommodate $S$ species. In addition, abundant active sites could also be provided for LiPSs adsorption/catalytic conversion. ${ }^{51}$

With a large special surface area, graphene is combined with other compounds with $2 \mathrm{D}$ structures (i.e., $\mathrm{MoS}_{2}, \mathrm{ReS}_{2}$,
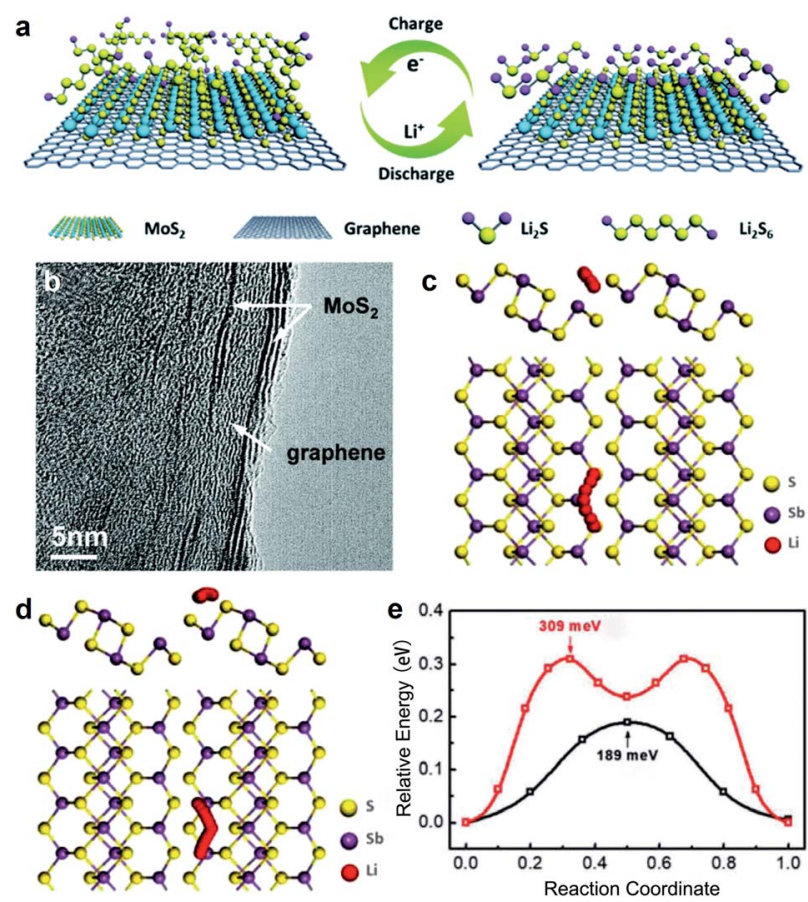

Fig. 3 (a) The conversion process of LiPSs on a graphene surface with $1 T \mathrm{MoS}_{2}$. (b) High-resolution TEM images of 3DG/TM. Reproduced with permission. ${ }^{55}$ Copyright 2019, The Royal Society of Chemistry. (c and d) Schematics of top and side views representing two Li diffusion pathways on $\mathrm{Sb}_{2} \mathrm{~S}_{3}$ nanosheets. (e) The corresponding energy profiles for different diffusion pathways in (c) (black curve) and (d) (red curve). Reproduced with permission. ${ }^{60}$ Copyright 2018, Wiley-VCH.
$\left.\mathrm{VSe}_{2}, \mathrm{VS}_{2}, \mathrm{TiS}_{2}\right){ }^{52-54}$ As the most typical example for graphene-based heterostructure, the independent threedimensional graphene/1T $\mathrm{MoS}_{2}$ (3DG/TM) heterostructure was designed (Fig. 3a). ${ }^{55}$ A unique 3DG/TM nanoarchitecture, constructed by few-layered $2 \mathrm{D} \mathrm{MoS}_{2}$ nanosheets in situ grown on a porous 3D graphene network, guarantees abundant active sites (Fig. 3b). ${ }^{56-58}$ Moreover, both the 3D graphene framework and metal $1 \mathrm{~T} \mathrm{MoS}_{2}$ nanosheets exhibit high conductivity, which greatly promotes electron transfer during charging and discharging process. Furthermore, the edge sites of 3DG/TM with a high aspect ratio, which possesses high catalytic ability, are beneficial to accelerate the redox reaction of sulfur. Taken together, the cells with 3DG/TM show excellent electrochemical performance, with a high reversible discharge capacity of $1181 \mathrm{~mA} \mathrm{~h} \mathrm{~g}^{-1}$ and a capacity retention rate of $96.3 \%$ after 200 cycles. He et al. reported $\mathrm{Nb}_{2} \mathrm{O}_{5}$ nanocrystals/reduced graphene oxide $\left(\mathrm{Nb}_{2} \mathrm{O}_{5} / \mathrm{RGO}\right)$ heterostructures with robust polysulfide traps and catalytic centers as a separator of $\mathrm{Li}-\mathrm{S}$ battery. ${ }^{59}$ Notably, thiosulfate detected in the discharge process via XPS spectra, indicated that $\mathrm{Nb}_{2} \mathrm{O}_{5}$ could trigger the thiosulfate redox pathway for Li-S batteries. Besides $2 \mathrm{D}$ graphene, CNT could also construct heterostructures with metal compounds. Kim and co-workers successfully combined $\mathrm{Sb}_{2} \mathrm{~S}_{3}$ with CNT (SSNSs/CNTs) based on van der Waals' force. ${ }^{60}$ Using DFT calculations, they studied the diffusion path and the corresponding energy distribution of lithium ions on SSNS surfaces (Fig. 3c and d). Notably, the lowest $\mathrm{Li}^{+}$diffusion energy barrier is $0.189 \mathrm{eV}$ for the SSNSs/ CNTs heterostructure with the bonding energy of LiPSs increased (Fig. 3e), which is beneficial for the rapid redox conversion of LiPSs. As a result, the SSNSs/CNTs supply highreversible specific capacity and stable cycling performance.

As a promising approach to alleviate the shuttle effect and promote the performance of the $\mathrm{Li}-\mathrm{S}$ battery, the nucleation and deposition progress of $\mathrm{Li}_{2} \mathrm{~S}$ during the discharge process also draws much attention. Owing to the polarization effect and low conductivity of sulfur host, the redox reaction of LiPSs cannot undergo concurrently, leading to unevenly deposited $\mathrm{Li}_{2} \mathrm{~S}$ on the electrode during LiPSs redox from the electrolyte to the electrode. ${ }^{23,61}$ Tian et al. reported that layered $\mathrm{MoSe}_{2}$ was decorated on rGO ( $\left.\mathrm{MoSe}_{2} @ \mathrm{arO}\right)$ for Li-S cathode. ${ }^{62}$ Due to the sulfiphilic $\mathrm{MoSe}_{2}$ and ultrahigh conductivity of rGO, the polarization problem is effectively alleviated. Hence, MoSe $\mathrm{C}_{2}$ @rGO not only facilitates the redox reaction of LiPSs but also promotes nucleation and uniform deposition of $\mathrm{Li}_{2} \mathrm{~S}$, which display a high initial capacity of $1608 \mathrm{~mA} \mathrm{~h} \mathrm{~g}^{-1}$ at $0.1 \mathrm{C}$, a slow decay rate of $0.042 \%$ per loop at $0.25 \mathrm{C}$, and a high reversible capacity of $870 \mathrm{~mA} \mathrm{~h} \mathrm{~g}^{-1}$ with an areal sulfur loading of $4.2 \mathrm{mg} \mathrm{cm}^{-2}$ at $0.3 \mathrm{C}$.

3.2. Metal compound-based heterostructures. Generally, the metal compound-based heterostructures could adjust the electronic structure of metal compounds, accelerate the diffusion of LiPSs from the capture site to the conductive matrix during a redox reaction, and achieve strong chemical interaction and high catalytic activity with LiPSs, thereby enhancing kinetics of LiPSs conversion. 


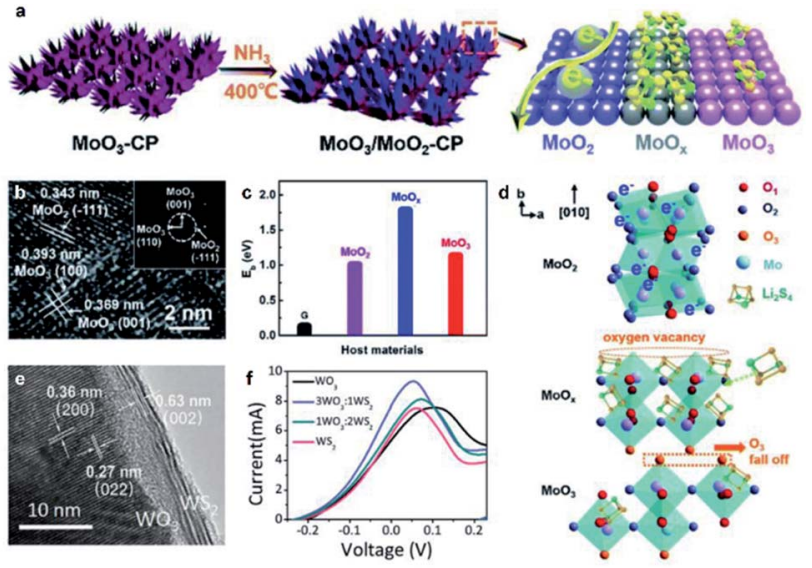

Fig. 4 (a) Schematic illustration of the synthesis process, the adsorption of LiPSs and electron transport on $\mathrm{MoO}_{3} / \mathrm{MoO}_{2}-\mathrm{CP}$. (b) HRTEM image of $\mathrm{MoO}_{3} / \mathrm{MoO}_{2}$. Inset: SAED patterns of $\mathrm{MoO}_{3}$ and $\mathrm{MoO}_{2}$. (c) Calculated binding strength for $\mathrm{Li}_{2} \mathrm{~S}_{4}$ on graphene (G), $\mathrm{MoO}_{2}$, $\mathrm{MoO}_{x}$ and $\mathrm{MoO}_{3}$, respectively. (d) Schematic diagram of the in situ phase transition to evolve into $\mathrm{MoO}_{3} / \mathrm{MoO}_{2}$ heterostructures and working principle in $\mathrm{Li}-\mathrm{S}$ batteries. $\mathrm{O}_{1}$ : asymmetric oxygens, $\mathrm{O}_{2}$ : coordinated oxygens, $\mathrm{O}_{3}$ : terminal oxygens. Reproduced with permission. ${ }^{66}$ Copyright 2020, The Royal Society of Chemistry. (e) HRTEM image of $\mathrm{WS}_{2}-\mathrm{WO}_{3}$ heterostructures. (f) Symmetric cyclic voltammogram of $\mathrm{Li}-\mathrm{S}$ batteries with $\mathrm{WS}_{2}-\mathrm{WO}_{3}$ heterostructure. Reproduced with permission. ${ }^{71}$ Copyright 2020, Wiley-VCH.

Metal oxides-based heterostructures can boost the conversion of LiPSs in the inverse charge/discharge process, due to the strong polarity of the metal-oxygen bond. ${ }^{63-65}$ Gong et al. reported an insulating $\mathrm{MoO}_{3} /$ conducting $\mathrm{MoO}_{2}$ heterostructure as the host of sulfur for Li-S battery (Fig. 4a). In this heterostructure, $\mathrm{MoO}_{3}$ and $\mathrm{MoO}_{2}$ coexist and form an articulated interface as $\mathrm{MoO}_{x}$ (Fig. 4b). Furthermore, compared with pure $\mathrm{MoO}_{3}$ and $\mathrm{MoO}_{2}$, the adsorption capacity of $\mathrm{MoO}_{x}$ for $\mathrm{Li}_{2} \mathrm{~S}_{4}$ is stronger (Fig. 4c), which could attribute to the defective structure of $\mathrm{MoO}_{x}$ (Fig. 4d). As a consequence, the $\mathrm{MoO}_{3} / \mathrm{MoO}_{2}$ heterostructure delivers an initial specific capacity of $580.5 \mathrm{~mA} \mathrm{~h} \mathrm{~g}^{-1}$ at $2.5 \mathrm{C}$ with a capacity retention of $82.8 \%$ after 850 cycles. ${ }^{66} \mathrm{Xu}$ and co-workers combined $\mathrm{NiO}$ and $\mathrm{NiCo}_{2} \mathrm{O}_{4}$ to produce NiO- $\mathrm{NiCo}_{2} \mathrm{O}_{4}$ heterostructure as a sulfur host for $\mathrm{Li}-\mathrm{S}$ batteries. They found that $\mathrm{NiO}-\mathrm{NiCo}_{2} \mathrm{O}_{4}$ heterostructure could significantly promote polysulfide conversion reactions and improve the electrical conductivity during cycling. ${ }^{67}$ In addition, metal oxide could also junction to sulfides, nitrides even carbide. For example, $\mathrm{WS}_{2}-\mathrm{WO}_{3}$ heterostructure could be prepared by in situ vulcanization of $\mathrm{WO}_{3}$, resulting in a large number of active interfacial active sites (Fig. 4e). As shown in Fig. 4f, compared with $\mathrm{WO}_{3}$, the redox peak of symmetric battery with $\mathrm{WS}_{2}-\mathrm{WO}_{3}$ electrode is narrower and the peak separation is smaller, ${ }^{68,69}$ indicating that the conversion capacity becomes higher due to the improved catalytic ability. ${ }^{70,71}$ Similarly, $\mathrm{SnS}_{2} / \mathrm{SnO}_{2}$ heterostructures, ${ }^{72} \mathrm{SnS}_{2} / \mathrm{TiO}_{2}$ heterostructures, ${ }^{73} \mathrm{Ti}_{2} \mathrm{CO} / \mathrm{WS}_{2}$ heterostructures ${ }^{74}$ also exhibit high conductivity, strong adsorption for LiPSs and catalysis for LiPSs conversion as a sulfur host for $\mathrm{Li}-\mathrm{S}$ batteries. Interestingly, recent research studies demonstrated that metal oxides generating heterostructures with nitrides realized the smooth trapping-diffusion-conversion of LiPSs for ultra-long life $\mathrm{Li}-\mathrm{S}$ batteries. Yang and co-workers constructed $\mathrm{TiO}_{2}-\mathrm{TiN}$ heterostructures, which combined the merits of highly adsorptive $\mathrm{TiO}_{2}$ with conducting TiN. In this special heterostructure, $\mathrm{TiO}_{2}$ with high adsorption for LiPSs coupled with catalytic TiN to

Table 2 Electrochemical properties of $\mathrm{Li}-\mathrm{S}$ batteries with deficient materials

\begin{tabular}{|c|c|c|c|c|c|}
\hline \multirow[b]{2}{*}{ Catalysis } & \multirow{2}{*}{$\begin{array}{l}\text { Sulfur loading } \\
\left(\mathrm{mg} \mathrm{cm}^{-2}\right)\end{array}$} & \multirow[b]{2}{*}{ Redox intermediate } & \multicolumn{2}{|l|}{ Performance } & \multirow[b]{2}{*}{ Ref. } \\
\hline & & & 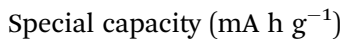 & Cycling stability & \\
\hline $\mathrm{OVs}^{-\mathrm{TiO}_{2} @ \mathrm{PP}}$ & 7.1 & LiPSs & 1148 at $0.5 \mathrm{C}$ & 500 cycles (decay rate of $0.043 \% /$ cycle at $2 \mathrm{C}$ ) & 109 \\
\hline CMNC-10 h & 2.7 & LiPSs & 829 at $1 \mathrm{C}$ & 500 cycles (decay rate of $0.045 \% /$ cycle at $1 \mathrm{C}$ ) & 107 \\
\hline $\mathrm{Fe} / \mathrm{Co}_{3} \mathrm{O}_{4}$ & - & LiPSs & 902.4 at $1 \mathrm{C}$ & 1000 cycles (decay rate of $0.017 \% /$ cycle at $1 \mathrm{C}$ ) & 129 \\
\hline $\mathrm{Fe}_{2} \mathrm{O}_{3} @ \mathrm{~N}-\mathrm{PC} / \mathrm{Mn}_{3} \mathrm{O}_{4}-\mathrm{S}$ & 5.1 & Thiosulfate & 1425 at $0.5 \mathrm{C}$ & 100 cycles (decay rate of $0.076 \% /$ cycle at $0.1 \mathrm{C}$ ) & 46 \\
\hline 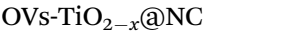 & 9.5 & Thiosulfate & 1372 at $0.2 \mathrm{C}$ & 3000 cycles (decay rate of $0.0123 \% /$ cycle at $5 \mathrm{C}$ ) & 130 \\
\hline $\mathrm{Ti}_{2} \mathrm{O}$ & 2.5 & LiPSs & 1063 at $0.5 \mathrm{C}$ & 500 cycles (decay rate of $0.04 \% /$ cycle at $0.5 \mathrm{C}$ ) & 131 \\
\hline $\mathrm{CNT@TiO}_{2-x}-\mathrm{S}$ & 8.6 & LiPSs & 1149 at $0.2 \mathrm{C}$ & 300 cycles (decay rate of $0.042 \% /$ cycle at $1 \mathrm{C}$ ) & 97 \\
\hline $\mathrm{MnO}_{x}-\mathrm{CeO}_{2} @ \mathrm{rGO}$ & 6 & Thiosulfate & 630 at $3 \mathrm{C}$ & 1000 cycles (decay rate of $0.036 \% /$ cycle at $1 \mathrm{C}$ ) & 70 \\
\hline $\mathrm{MnO}_{2}$ & 1.5 & Thiosulfate & 1053 at $0.5 \mathrm{C}$ & 400 cycles (decay rate of $0.09 \% /$ cycle at $2 \mathrm{C}$ ) & 132 \\
\hline CNTs@FeOOH & - & LiPSs & 630.8 at $2 \mathrm{C}$ & - & 83 \\
\hline $\mathrm{La}(\mathrm{OH})_{3}$ & 5.7 & LiPSs & 1160.4 at $0.2 \mathrm{C}$ & 100 cycles (decay rate of $0.223 \% /$ cycle at $0.2 \mathrm{C}$ ) & 108 \\
\hline CSUST-1/CNT & 2 & Thiosulfate & 1468 at $0.1 \mathrm{C}$ & 1200 cycles (decay rate of $0.037 \% /$ cycle at $2 \mathrm{C}$ ) & 110 \\
\hline SnS/PCNS & 1.5 & LiPSs & 1270 at $0.5 \mathrm{C}$ & 800 cycles (decay rate of $0.039 \% /$ cycle at $1 \mathrm{C}$ ) & 120 \\
\hline $\mathrm{SnS}_{2} / \mathrm{TiO}_{2}$ & - & LiPSs & 1064 at $0.5 \mathrm{C}$ & 500 cycles (decay rate of $0.064 \% /$ cycle at $0.5 \mathrm{C}$ ) & 122 \\
\hline MXene/1T-2H $\mathrm{MoS}_{2}-\mathrm{C}$ & 1.0 & LiPSs & 1194.7 at $0.1 \mathrm{C}$ & 300 cycles (decay rate of $0.07 \% /$ cycle at $0.5 \mathrm{C}$ ) & 118 \\
\hline MoP/MoS @C $_{2}$ & 4.0 & Thiosulfate & 517.1 at $5 \mathrm{C}$ & 500 cycles (decay rate of $0.065 \% /$ cycle at $0.5 \mathrm{C}$ ) & 133 \\
\hline $\mathrm{Co}_{3} \mathrm{~S}_{4}$-DHS & 2.6 & LiPSs & 1090 at $0.1 \mathrm{C}$ & 400 cycles (decay rate of $0.17 \% /$ cycle at $1 \mathrm{C}$ ) & 134 \\
\hline $3 \mathrm{DOM} \mathrm{N}-\mathrm{Co}_{9} \mathrm{~S}_{8-x}$ & 6.5 & LiPSs & 812.8 at $5 \mathrm{C}$ & 500 cycles (decay rate of $0.04 \% /$ cycle at $1 \mathrm{C}$ ) & 115 \\
\hline $\mathrm{MoS}_{2-x}$ & - & LiPSs & 826.5 at $8 \mathrm{C}$ & 600 cycles (decay rate of $0.083 \% /$ cycle at $0.5 \mathrm{C}$ ) & 69 \\
\hline $\mathrm{Ni}_{3} \mathrm{~N}_{0.85}$ & 1.5 & LiPSs & 1445.9 at $0.02 \mathrm{C}$ & 1000 cycles (decay rate of $0.039 \% /$ cycle at $2 \mathrm{C}$ ) & 128 \\
\hline $\mathrm{Co}_{5.47} \mathrm{~N}_{x}-\mathrm{C}$ & - & Thiosulfate & 850 at $0.5 \mathrm{C}$ & 1000 cycles (decay rate of $0.04 \% /$ cycle at $2 \mathrm{C}$ ) & 127 \\
\hline
\end{tabular}


achieve both high trapping efficiency and fast conversion. As a result, the $\mathrm{Li}-\mathrm{S}$ cell with $\mathrm{TiO}_{2}-\mathrm{TiN}$ as a sulfur host delivered a capacity of $927 \mathrm{~mA} \mathrm{~h} \mathrm{~g}^{-1}$ after 300 cycles under a low current density of $0.3 \mathrm{C} .{ }^{75} \mathrm{Lu}$ et al. designed $\mathrm{V}_{2} \mathrm{O}_{3} / \mathrm{V}_{8} \mathrm{C}_{7}$ heterostructures derived to suppress the shuttle effect and enhance the kinetics of LiPSs, which was realized by forming thiosulfate for LiPSs conversion. ${ }^{76}$

Recently, metal sulfide-based heterostructures (i.e., $\mathrm{MoS}_{2}-$ $\left.\mathrm{Ni}_{3} \mathrm{~S}_{2}, \quad \mathrm{NiS}_{2}-\mathrm{ZnS}, \quad \mathrm{Co}_{3} \mathrm{~S}_{4}-\mathrm{MnS}\right)$ and nitride-based heterostructures (i.e., MoN-VN) are constructed to facilitate LiPSs conversion and offer strong adsorption for LiPSs. ${ }^{77-81}$ Due to their higher conductivity than metal oxides, metal sulfide-based heterostructures and nitride-based heterostructures exhibit superb electron and ion transfer rates. Pan et al. reported a novel 2D hexagonal $\mathrm{WS}_{2}$-rimmed $\mathrm{Co}_{9} \mathrm{~S}_{8}$ heterostructure nanosheet, which was loaded on the surface of CNF skeletons as a sulfur host for Li-S battery. In this heterostructure, the $\mathrm{WS}_{2}$ component grew at the edge of hexagonal $\mathrm{Co}_{9} \mathrm{~S}_{8}$ nanosheets and optimized the synergistic effect on the electrochemical kinetics of the composite cathode, which increased the capacity (1175 $\mathrm{mA} \mathrm{h} \mathrm{g}^{-1}$ at $0.1 \mathrm{C}$ ) and stability (a low decay rate of $0.061 \%$ per cycle at 2.0C, even lower at 7.0C and 12.0C) of assembled $\mathrm{Li}-$ $\mathrm{S}$ batteries. ${ }^{82} \mathrm{Yu}$ et al. designed a conductive frame by integrating independent carbon nanofibers and TiN-VN heterostructure (TiN-VN@CNFs) into the high-level full battery as S cathode and Li anode. ${ }^{83}$ As a sulfur host, TiN-VN@CNFs exhibits advantages of strong anchoring ability and rapid conversion of LiPSs, which greatly inhibit the shuttle of LiPSs. It is noted that TiN-VN@CNFs can oxide LiPSs to thiosulfate during the discharge process. Furthermore, as an anode, TiN-VN@CNFs substrates with lithiophilic properties could reduce local electron/ion flux when applied in $\mathrm{Li}$ substrates, thereby achieving uniform Li deposition and inhibiting the growth of dendrites. Taken together, the coupled Li-S full battery shows perfect sulfur utilization and highly reversible lithium dissolution/plating, resulting in excellent rating capacity (650 $\mathrm{mA} \mathrm{h} \mathrm{g}^{-1}$ at 5C) and a long cycle life of more than 600 cycles (capacity decay only $0.051 \%$ per cycle).

3.3. Other heterostructures. Recently, conductive polymers (polypyrrole (PPy), polyethylene glycol (PEG), polyaniline (PANI), polyvinylidene fluoride (PVDF)) and other conductive compounds (i.e., MXene) have become an ideal platform for $\mathrm{Li}-$ $\mathrm{S}$ batteries due to their inherent conductive nature, nitrogencontaining functional groups and conjugated structure. ${ }^{84}$ Due to the combination of excellent electronic conductivity and considerable adsorption effect, hybridization of conductive matrix/metal compound has become a common strategy for constructing sulfur heterostructure hosts.

Chen et al. prepared an $\mathrm{H}_{-}-\mathrm{TiO}_{x}$ material with high conductivity and strong polarity properties through a simple magnesium thermal reduction method, and then this material was combined with the conductive polymer PPy coating for the preparation of Li-S battery cathode. ${ }^{85}$ Due to the synergistic effect of $\mathrm{H}^{-\mathrm{TiO}_{x}}$ (accelerating conversion and absorption of LiPSs) and PPy (high conductivity), the diffusion of LiPSs can be sufficiently inhibited by forming Ti-S bonds (Lewis acid-base interaction), Li-N bonds (polar-polar interaction) and physical limitation of the PPy layer. This lead to a significant prolongation of the Li-S battery cycle life. Notably, due to their excellent conductivity, 2D structure, and Lewis acidic surface, MXene exhibits great potentials in a wealth of energy storage applications. ${ }^{86-88}$ Yang and co-workers crafted the $\mathrm{TiO}_{2}-\mathrm{MXene}$ $\left(\mathrm{Ti}_{3} \mathrm{C}_{2} \mathrm{~T}_{x}\right)$ heterostructures for Li-S batteries. ${ }^{47}$ They demonstrated that the $\mathrm{TiO}_{2} / \mathrm{MXene}$ hetero-interface delivers rapid diffusion of polysulfides from $\mathrm{TiO}_{2}$ to MXene, and the MXene surface with a large special surface area is endowed with abundant capturing centers to immobilize polysulfides high catalytic activity toward polysulfide conversion. Consequently, $\mathrm{Li}-\mathrm{S}$ batteries with $\mathrm{TiO}_{2}-\mathrm{MXene}$ heterostructures show a special capacity of $800 \mathrm{~mA} \mathrm{~h}^{-1}$ at $2 \mathrm{C}$ and an ultralow capacity decay of $0.028 \%$ per cycle over 1000 cycles at $2 \mathrm{C}$.

\section{Deficiency strategy}

Recent studies have revealed the great ability of defect engineering in altering the physicochemical and electronic structure for enhanced adsorptive and catalytic features, which provide a promising way to achieve strong polysulfides confirmation and simultaneously accelerate the conversion of LiPSs in the Li-S system. ${ }^{96-99}$ Deficiency strategy, including oxygen vacancies, sulfur vacancy and nitrogen-vacancy, holds a great promise in promoting practical applications of $\mathrm{Li}-\mathrm{S}$ batteries as well as enlightening the material engineering in related energy storage and conversion areas. ${ }^{\mathbf{1 0 0}}$ Table 2 exhibits the

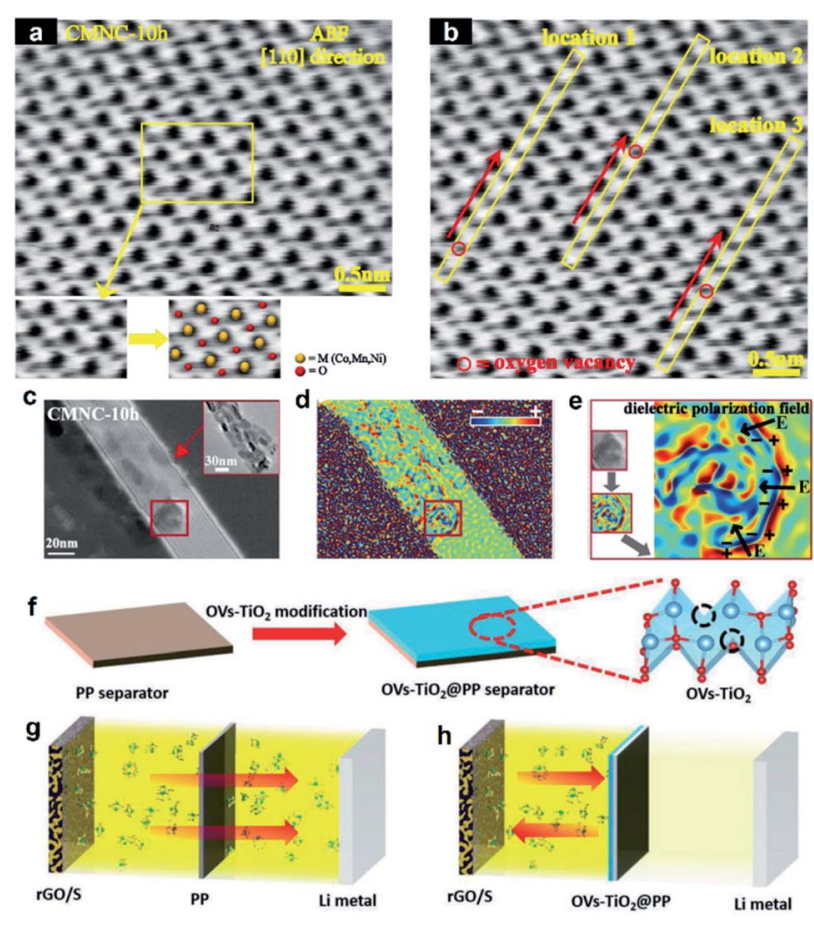

Fig. 5 (a and b) Annular bright-field (ABF) images, (c) hologram, (d) charge density map and (e) dielectric polarization field for CMNC-10 h. Reproduced with permission. ${ }^{107}$ Copyright 2019, American Chemical Society. (f) Schematic for the fabrication of OVs- $\mathrm{TiO}_{2}$ @PP separator. A mechanism for inhibiting the shuttle effect of the PP separator $(\mathrm{g})$ and OVs- $\mathrm{TiO}_{2}$ (aPP separator (h). Reproduced with permission. ${ }^{109}$ Copyright 2020, Wiley-VCH. 
electrochemical properties of $\mathrm{Li}-\mathrm{S}$ batteries with deficiency nanomaterials.

4.1 Oxygen vacancy. Oxygen vacancy, a common type of surface defect, has been widely concerned in the field of catalysis. ${ }^{101-103}$ First, oxygen vacancies with abundant localized electrons are considered active sites for the adsorption and activation of adsorbent molecules. ${ }^{104}$ In addition, the recombination of charge carriers is effectively suppressed due to the strong electron and/or hole trapping ability of surface oxygen vacancies, which could remarkably reduce the energy barrier for interfacial charge transfer. ${ }^{\mathbf{1 0 5 , 1 0 6}}$ Subsequently, oxygen vacancies can significantly promote electrochemical properties of $\mathrm{Li}-\mathrm{S}$ batteries by means of promoting affinity with LiPSs and enhancing conductivity.

Currently, oxygen vacancies in metal oxides such as $\mathrm{TiO}_{2}$, $\mathrm{Mn}_{x} \mathrm{O}_{y}, \mathrm{Fe}_{2} \mathrm{O}_{3}$, and $\mathrm{CoO}$, can generate rich electrons, leading to high conductivity and promote the conversion rate of LiPSs. Wang et al. synthesized dandelion-like $\mathrm{Mn} / \mathrm{Ni}$ co-doped $\mathrm{CoO} / \mathrm{C}$ hollow microspheres (CMNC-10 h) with oxygen vacancies as sulfur host (Fig. 5a and b). ${ }^{107}$ They found that the oxygen vacancies in superficial regions of nanoparticles trigger redistribution of charge (Fig. 5c). Concretely, the positive charge accumulates on the outside surfaces of nanoparticles, and the negative charge aggregate on internal surfaces (Fig. 5d and e). This highly delocalized electronic structure can remarkably improve the conductivity of nanoparticles, resulting in enhancing electrochemical kinetics. Consequently, CMNC-10 h provides a high capacity of $642 \mathrm{~mA} \mathrm{~h} \mathrm{~g}^{-1}$ after 500 cycles at $1 \mathrm{C}$. Sun and co-workers reported a yolkshell $\mathrm{Fe}_{2} \mathrm{O}_{3} @ \mathrm{~N}-\mathrm{PC} / \mathrm{Mn}_{3} \mathrm{O}_{4}$ sulfur host, in which oxygen vacancy induced an interfacial charge field. Intriguingly, polysulfide was oxidised to thiosulfate on defective $\mathrm{Fe}_{2} \mathrm{O}_{3} @ \mathrm{~N}-\mathrm{PC} /$ $\mathrm{Mn}_{3} \mathrm{O}_{4}$ surface, leading to immobilizing and catalysing the conversion of LiPSs. ${ }^{46}$ In addition to the above metal oxides, oxygen vacancies are also discovered in metal hydroxides for enhancing conductivity and catalytic properties. Tian et al. synthesized oxygen-deficient $\mathrm{La}(\mathrm{OH})_{3}$ composed of reduced graphene oxide as a host material for sulfur with superb conductivity. ${ }^{108} \mathrm{La}(\mathrm{OH})_{3}$ nanorods with abundant oxygen vacancies were employed to promote the reversibility of LiPSs. Sun and co-workers reported a high catalytically active CNTs@FeOOH composite with rich oxygen vacancies, which could function as an electrocatalyst and promote the catalytic conversion of intercepted LiPS. ${ }^{83}$ As a result, the optimized CNTs@FeOOH interlayer contributed to a high reversible capacity of $556 \mathrm{~mA} \mathrm{~h} \mathrm{~g}{ }^{-1}$ over 350 cycles.
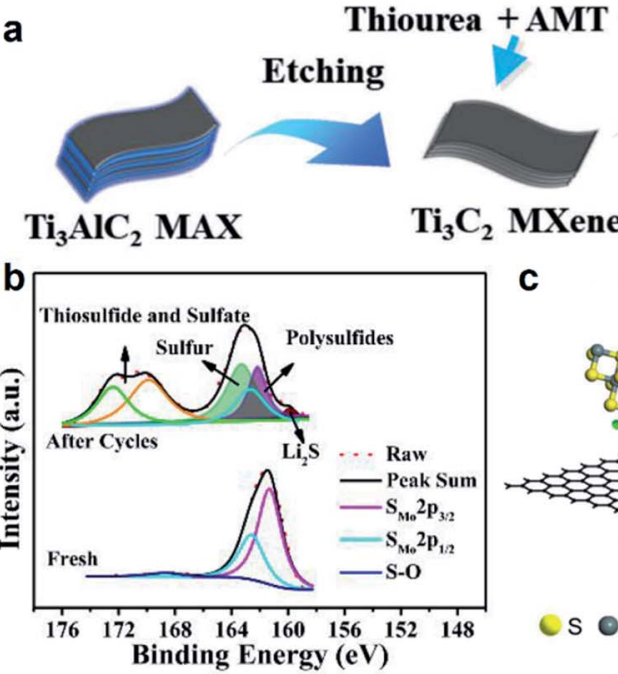

\section{C}
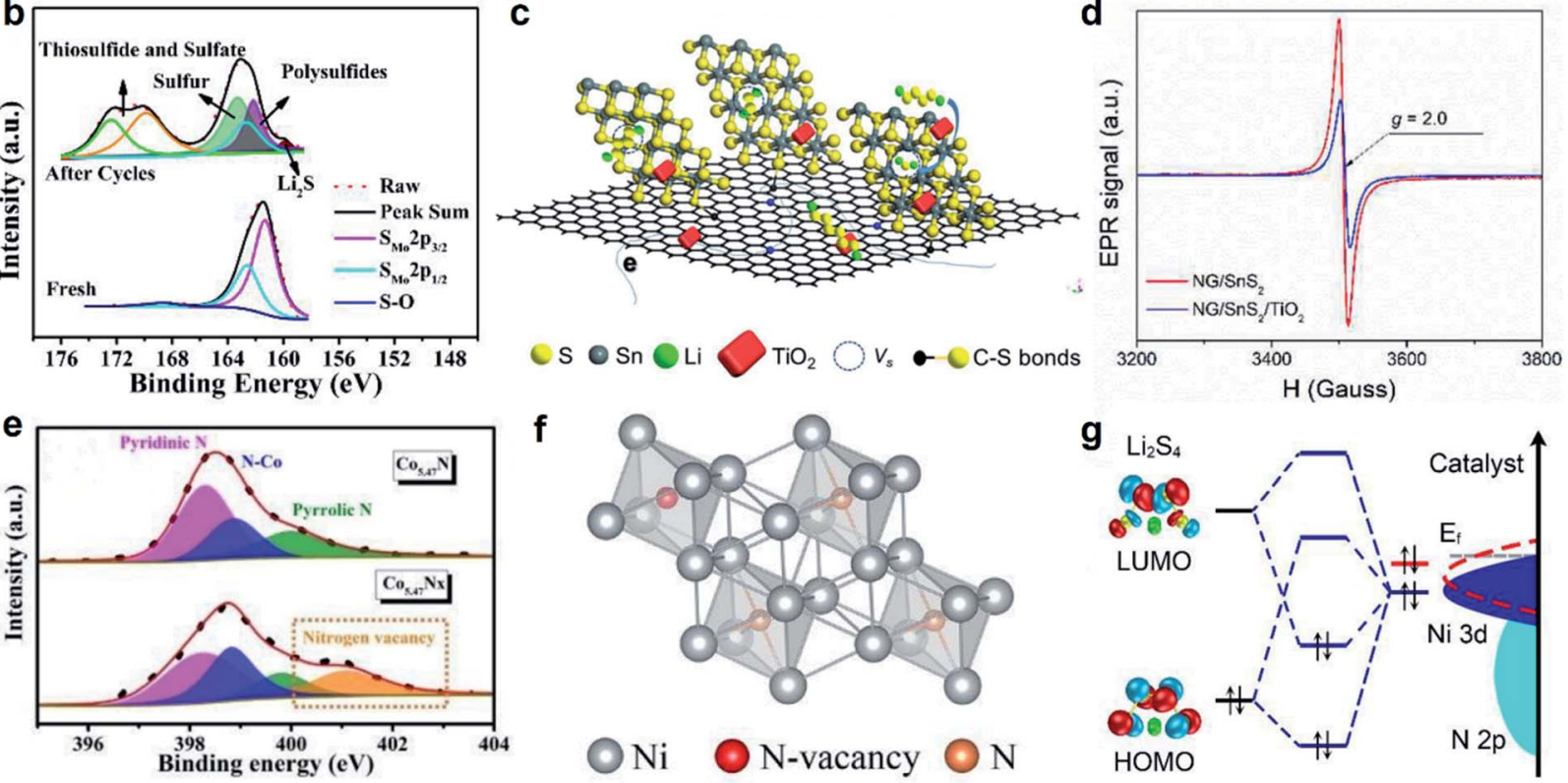

f
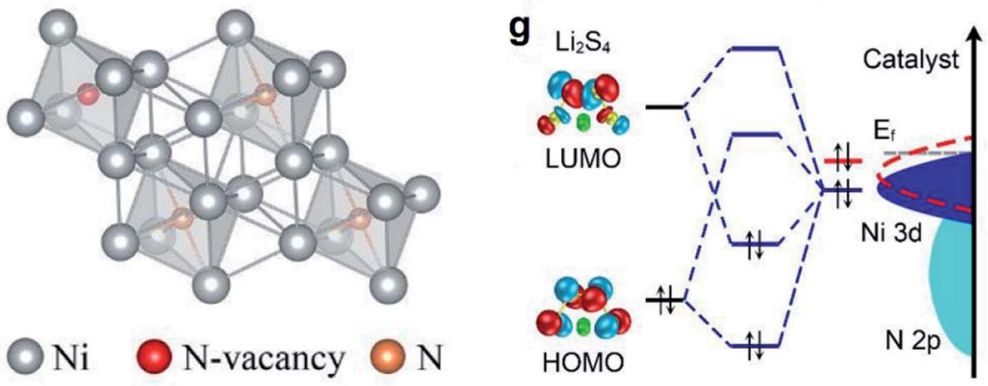

Fig. 6 (a) Schematic illustration of the fabrication process of MXene/1T-2H MoS $-\mathrm{C}$ composites. Reproduced with permission. ${ }^{109}$ Copyright 2018, Wiley-VCH. (b) S $2 p$ spectral regions of MoP/MoS 2 aC modified separator before and after 50 cycles. Reproduced with permission. ${ }^{118}$ Copyright 2019, American Chemical Society. (c) Scheme of structural features of $\mathrm{NG} / \mathrm{SnS}_{2} / \mathrm{TiO}_{2}-\mathrm{S}$ in Li-S batteries. (d) EPR spectra of NG/SnS 2 and NG/SnS $2 / \mathrm{TiO}_{2}$. Reproduced with permission. ${ }^{122}$ Copyright 2018, The Royal Society of Chemistry. (e) High-resolution XPS of N 1s for CO $5.47 \mathrm{~N}_{x}$ and $\mathrm{CO}_{5.47} \mathrm{~N}$. Reproduced with permission. ${ }^{127}$ Copyright 2020, The Royal Society of Chemistry. (f) Crystal structure of Ni $\mathrm{N}_{0.85}$ for DFT calculations. (g) Orbital interactions between polysulfides and catalysts. Reproduced with permission. ${ }^{128}$ Copyright 2020, American Chemical Society. 
Recent research works show that separator could play the same catalytic function for LiPSs conversion as a sulfur host in the Li-S battery. Mai and co-workers decorated a commercial polypropylene (PP) separator with oxygen vacancy-rich $\mathrm{TiO}_{2}$

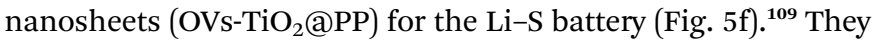
found that $\mathrm{OVs}^{-\mathrm{TiO}_{2}}$ exhibits excellent ionic conductivity, strong adsorption ability on polysulfides and robust catalytic ability, due to abundant suspended unsaturated bonds on OVs$\mathrm{TiO}_{2}$ surface. Taken together, the OVs-TiO ${ }_{2} @ P P$ separator can significantly suppress the LiPSs shuttling (Fig. $5 \mathrm{~g}$ and $\mathrm{h}$ ), and thus, show persistent cycling stability under a high current density of $2.0 \mathrm{C}$ over 500 cycles. Jin et al. reported an oxygen vacancy-rich cerium metal-organic framework (CSUST-1/CNT) for the Li-S battery separator. ${ }^{110}$ The abundant oxygen vacancies can remarkably accelerate the redox kinetics of polysulfides and $\mathrm{Li}^{+}$transportation. Consequently, the Li-S battery with the CSUST-1/CNT-coated separator displayed a high initial specific capacity of $1468 \mathrm{~mA} \mathrm{~h} \mathrm{~g}^{-1}$ at $0.1 \mathrm{C}$ and maintained long-term stability for a capacity of $538 \mathrm{~mA} \mathrm{~h} \mathrm{~g}^{-1}$ after 1200 cycles at 2C with a decay rate of only $0.037 \%$ per cycle.

4.2 Sulfur vacancy. Transition metal sulfides (TMSs) are widely believed to play a significant role in the catalysis of $\mathrm{Li}-\mathrm{S}$ batteries. For example, Xue and co-workers designed an intercalation-conversion hybrid cathode for $\mathrm{Li}-\mathrm{S}$ batteries by using $\mathrm{Mo}_{6} \mathrm{~S}_{8}$ as a sulfur host, in which $\mathrm{Mo}_{6} \mathrm{~S}_{8}$ could immobilize sulfur species and unlock its high gravimetric capacity due to the electrochemically active Chevrel-phase $\mathrm{Mo}_{6} \mathrm{~S}_{8}$ with self-active capacity contribution and strong LiPSs affinity. ${ }^{111,112}$ The other TMSs (i.e., $\mathrm{MoS}_{2}$, FeS, $\mathrm{VS}_{2}$, $\mathrm{TiS}_{2}$ ) were also investigated as sulfur hosts to propel the polysulfide redox reaction process. ${ }^{\mathbf{5 2 - 5 4}}$ Nevertheless, the electrical conductivity of TMSs is still not sufficient. ${ }^{113,114}$ Sulfur vacancy is based on TMSs, which introduce positive charge defects. ${ }^{115}$ These abundant positively charged defects can not only effectively trap the polysulfides, but also dynamically enhance polysulfide redox reaction.

TMSs are usually composited with conductive matrix (i.e., graphene, CNT, MXene) for promoting electron transfer. ${ }^{\mathbf{1 1 6 , 1 1 7}}$ Guo et al. proposed MXene/1T-2H $\mathrm{MoS}_{2}-\mathrm{C}$ nanohybrids with sulfur vacancies for boosting the performance of $\mathrm{Li}-\mathrm{S}$ batteries (Fig. 6a). ${ }^{118}$ It is found that the plentiful positively charged sulfur vacancies can serve as strong adsorption and activation sites for polar polysulfide intermediates, accelerate redox reactions, and prevent the dissolution of polysulfides. As a consequence, the MXene/1T-2H $\mathrm{MoS}_{2}-\mathrm{C}-\mathrm{S}$ cathode delivers a high initial capacity of $1194.7 \mathrm{~mA} \mathrm{~h} \mathrm{~g}^{-1}$ at $0.1 \mathrm{C}$, and a high level of capacity retention of $799.3 \mathrm{~mA} \mathrm{~h} \mathrm{~g}^{-1}$ after 300 cycles at $0.5 \mathrm{C}$. Yang et al. introduced sulfur deficiencies into $\mathrm{MoS}_{2-x}$ to enhance the conductivity. They proposed that sulfur deficiencies may enhance LiPSs reduction through some metastable S radicals, which contribute largely to LiPSs reactions. ${ }^{69}$ In addition, Huang and co-workers reported sulfur vacancies in $\mathrm{ZnS}$ composited with $\mathrm{rGO}\left(\mathrm{ZnS}_{1-x} / \mathrm{rGO}\right)$ and sulfur deficiencies can act as active sites to adsorb and convert LiPSs by generating $S$ radicals. ${ }^{119}$ Moreover, as the inherent $\mathrm{S}$ vacancy, SnS provides strong adsorption capability for LiPS, and thus delivers an initial capacity of $1270 \mathrm{~mA} \mathrm{~h}^{-1}$ at $0.5 \mathrm{C}$ as well as the slow decay rate of $0.039 \%$ per cycle at 1 C. ${ }^{120}$
Recently, sulfur vacancies are also introduced into TMSs heterostructures, which is employed to promote the conductivity of TMSs, leading to modulating the electron description and facilitating redox reactions. Wang and co-workers demonstrated that the sulfur vacancies generated in $\mathrm{MoP} / \mathrm{MoS}_{2}$ heterostructure also display the ability to incorporate lithiophilic and sulfophilic sites for LiPSs confinement and electrocatalysis through thiosulfate and sulfate (Fig. 6b). ${ }^{121}$ In addition, Wang et al. demonstrated that a controlled growth of sulfur-defectsrich $\mathrm{SnS}_{2} / \mathrm{TiO}_{2}$ nanocrystals on nitrogen-doped graphene (NG/ $\mathrm{SnS}_{2} / \mathrm{TiO}$ ) can serve as strong adsorption and activation sites for polar polysulfide intermediates, prevent their dissolution/ shuttling and accelerate their redox reactions (Fig. 6c and d). ${ }^{122}$ Consequently, the resultant $\mathrm{NG} / \mathrm{SnS}_{2} / \mathrm{TiO}_{2}-\mathrm{S}$ cathode achieves a high capacity of $1064 \mathrm{~mA} \mathrm{~h} \mathrm{~g}^{-1}$ at $0.5 \mathrm{C}$ and superior cyclability.

4.3 Nitrogen vacancy. Transition metal nitrides are used as sulfur hosts in Li-S batteries with the best conductivity, compared with oxides and sulfides. ${ }^{\mathbf{1 2 3 - 1 2 5}}$ Furthermore, recent research works have confirmed that nitrogen vacancies in nitrides could strongly affect local electronic structures and the atoms around the vacancies will be reactive, thus effectively catalyzing the conversion of LiPSs from $\mathrm{Li}_{2} \mathrm{~S}_{8}$ to $\mathrm{Li}_{2} \mathrm{~S}$ around the nitrogen vacancies. ${ }^{\mathbf{1 2 6}}$

Traditionally, transition metal nitrides are synthesized by oxides transformation in ammonia at high temperatures. Wang and co-workers synthesized cobalt nitride with nitrogen vacancies in nanoparticles $\left(\mathrm{Co}_{5.47} \mathrm{~N}_{x}-\mathrm{C}\right)$ via annealing the zeolite imidazole framework (ZIF-67) precursor in ammonia. ${ }^{127}$ They found that during high-temperature calcination, several nitrogen atoms were absent from the octahedral interstitial sites, leading to abundant nitrogen-vacancy (Fig. 6e). It is noted that LiPSs redox reaction kinetics of $\mathrm{Co}_{5.47} \mathrm{~N}_{x}-\mathrm{C}$ cathode with

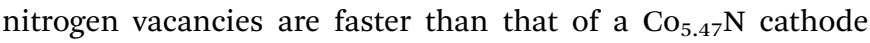
without nitrogen vacancies and thus achieving a promising rate and cycling performance for Li-S battery. In addition, Zhang et al. proposed a reasonable strategy to adjust the catalyst dband of $\mathrm{Ni}_{3} \mathrm{~N}$ to accelerate the conversion of polysulfide via nitrogen-vacancy $\left(\mathrm{Ni}_{3} \mathrm{~N}_{0.85}\right) \cdot{ }^{128}$ After the formation of nitrogen vacancies, more electrons migrate to the lowest occupied molecular orbital of $\mathrm{Li}_{2} \mathrm{~S}_{4}$, weakening the terminal $\mathrm{S}-\mathrm{S}$ bond, and suggesting that the conversion of polysulfides is accelerated (Fig. 6f and g). As a result, the $\mathrm{Ni}_{3} \mathrm{~N}_{0.85}$ cell displays an initial capacity of $1200 \mathrm{~mA} \mathrm{~h} \mathrm{~g}^{-1}$ for up to 100 cycles at a high loading of $5.2 \mathrm{mg} \mathrm{cm}^{-2}$.

\section{Heteroatom doping strategy}

Due to the excellent sulfur regulation ability and strong affinity for LiPSs, the heteroatom doping strategy is widely used to promote cycling ability and rate capability in Li-S batteries. ${ }^{\mathbf{1 3 5 - 1 3 8}}$ It is noted that the chemical affinity in polarpolar interaction is more favorable with respect to anchoring polysulfides. ${ }^{\mathbf{1 3 9}}$ Hence, a large number of works have been done on introducing polar sites into the sulfur host by heteroatom doping, including non-metal atoms (i.e., O, N, S, B) and metal atoms (i.e., Sn, Fe), to enhance the interaction between LiPSs 
Table 3 Electrochemical properties of Li-S batteries with heteroatom doped nanomaterials

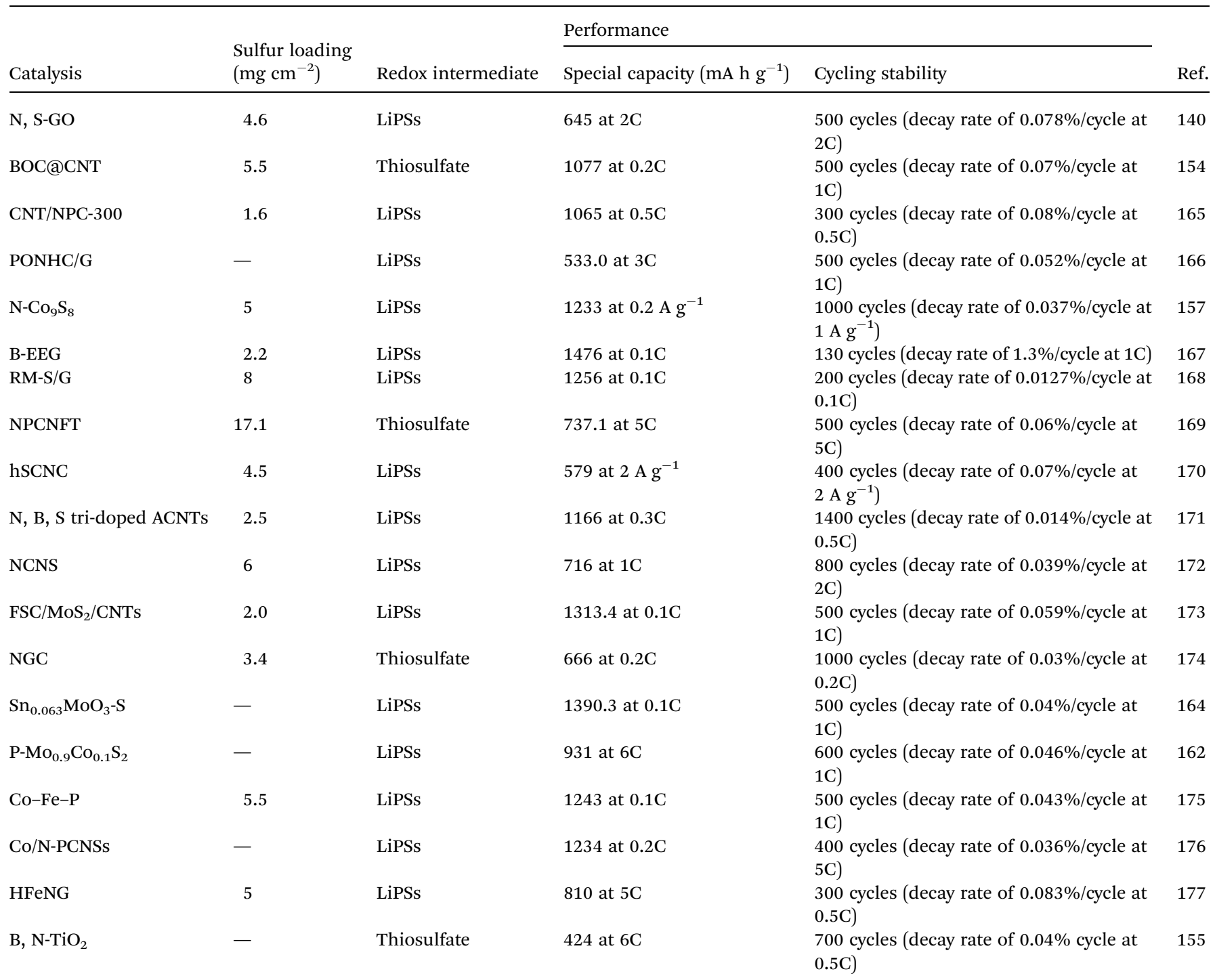

and the sulfur host. ${ }^{\mathbf{1 4 0 - 1 4 4}}$ Moreover, some researchers have clarified that heteroatom doping strategy not only generates abundant polar sites for LiPSs absorption but also promotes the conductivity of sulfur host, especially for transition metal oxides and sulfides, ${ }^{\mathbf{1 4 5}}$ achieving a fast LiPSs conversion. Subsequently, the LiPSs confinement could be realized by the sulfur host with ample polar sites that can simultaneously enhance the adsorption ability for LiPSs and conductivity. ${ }^{\mathbf{1 4 6 , 1 4 7}}$ Table 3 shows the electrochemical properties of $\mathrm{Li}-\mathrm{S}$ batteries with heteroatom doped nanomaterials.

5.1 Non-metal atom-doping strategy. Non-metal atom doping in scaffolds mitigates diffusion of dissolved LiPSs via strong chemical adsorption, which is favorable for the high utilization of sulfur in the active material for Li-S batteries. ${ }^{\mathbf{1 4 8 - 1 5 0}}$ Especially, non-metal atom doped carbon materials as sulfur hosts have been widely used to improve the electrochemical performance of Li-S batteries. ${ }^{151}$ Non-metal atom doping into carbon materials not only modulates the uniform distribution of electrons of nonpolar carbon surface to local electron accumulation in heteroatom but also creates special surface functional groups, which offer more active sites for LiPSs adsorption. ${ }^{152}$ It has been proved that these changes synergistically enhance the chemical adsorption of carbon to sulfur species, and have been intensively investigated to sequestrate soluble long-chain LiPSs in the cathode of Li-S batteries. ${ }^{\mathbf{1 5 3}}$

It is widely accepted that introducing $\mathrm{N}, \mathrm{S}, \mathrm{P}$ and $\mathrm{B}$ atoms into the carbon hosts could improve the performance of the $\mathrm{Li}$ $S$ battery. These heteroatoms can generate rich polar sites and produce sulfur radicals, thereby elongating the bond and even catalyzing polysulfides conversion. ${ }^{\mathbf{1 4 0 , 1 5 2}}$ Recent works have confirmed that compared with a single kind of atom doping, multiply atoms co-doped into a matrix could generate synergies on LiPSs adsorption and conversion. Manthiram and coworkers reported three-dimensional nitrogen/sulfur co-doped graphene sponge as a $\mathrm{Li}-\mathrm{S}$ battery cathode, in which thiourea was employed as nitrogen/sulfur sources (Fig. 7a). ${ }^{\mathbf{1 4 0}}$ They have 


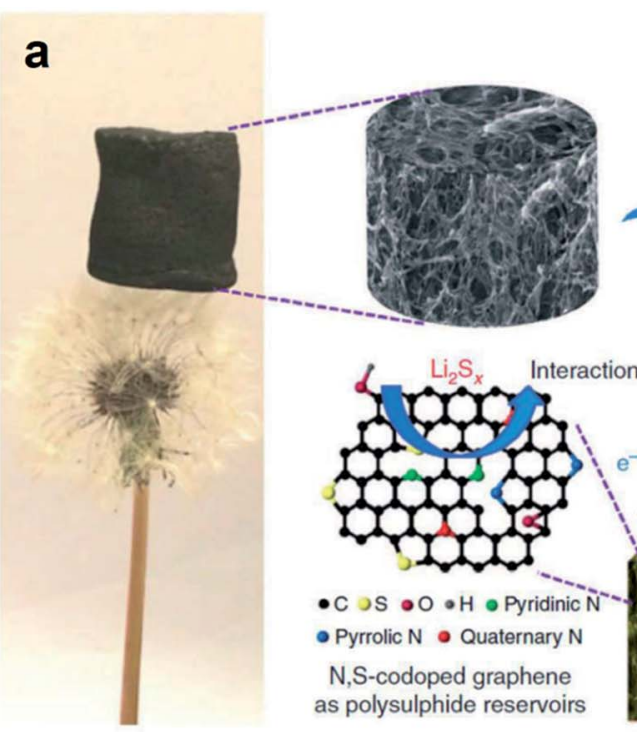

LiPSs shuttle

e

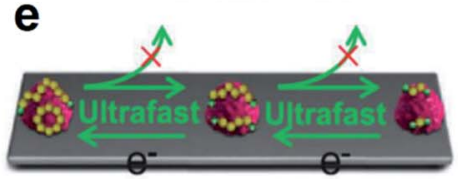

f

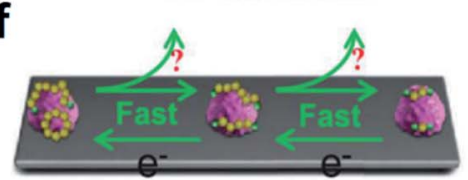

LiPSs shuttle

$\mathrm{N}-\mathrm{Co}_{9} \mathrm{~S}_{8} \quad \mathrm{Co}_{9} \mathrm{~S}_{8}$

Carbon paper

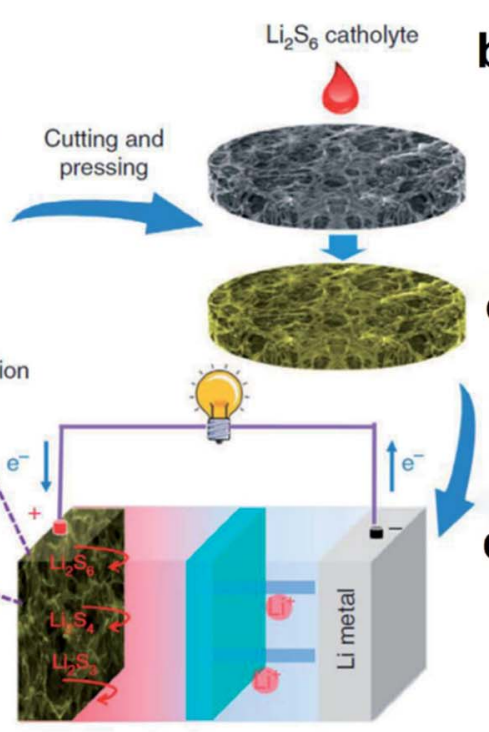

.

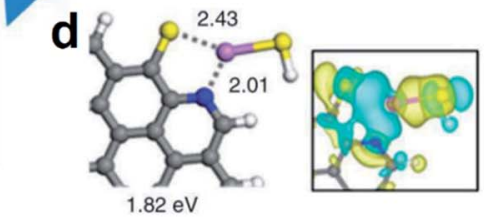

LiPSs shuttle

g
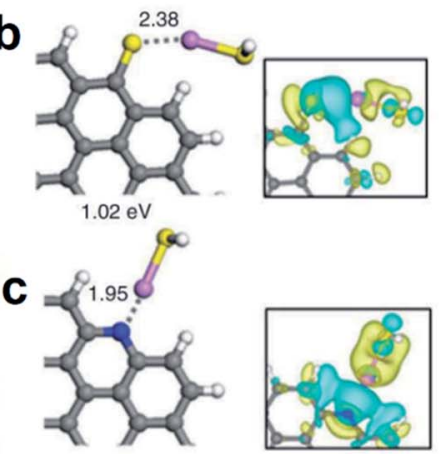

$1.29 \mathrm{eV}$
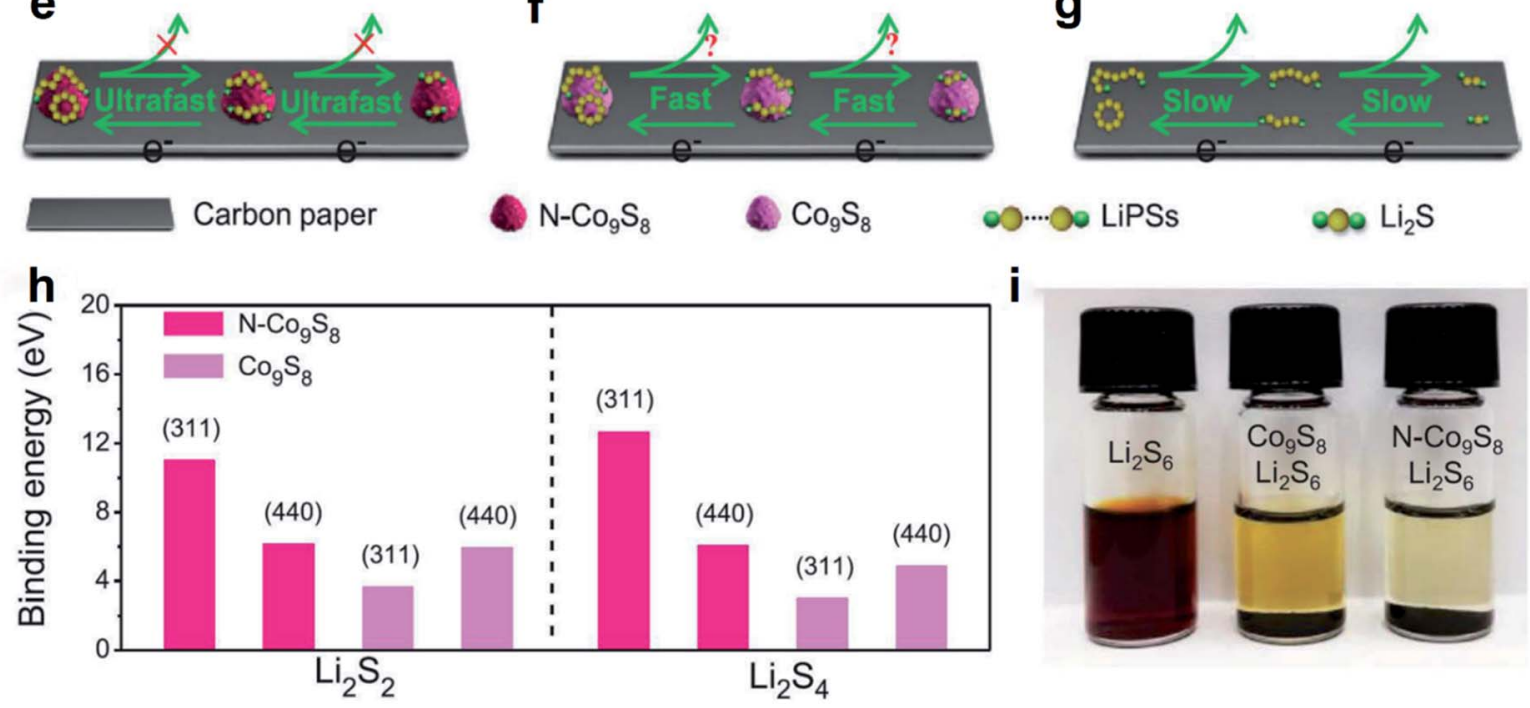

๑...๑ LiPSs

$\infty \mathrm{Li}_{2} \mathrm{~S}$

i

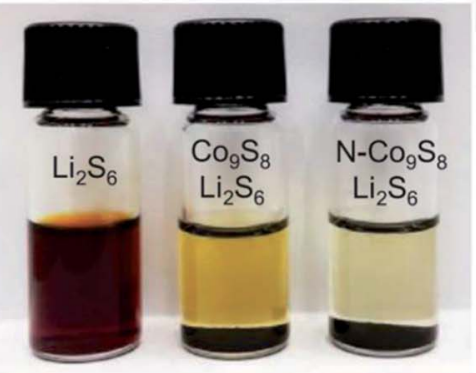

Fig. 7 (a) Illustration of the formation process of the N, S-co-doped graphene electrode, and a schematic of the fabrication of a Li/dissolved polysulphide cell with N, S-co-doped graphene electrode after adding polysulphide catholyte. Optimized configurations of LiSH binding to Sdoped graphene (b), N-doped graphene (c) and N, S-co-doped graphene (d), respectively. Insets: charge density difference isosurfaces; the blue and yellow colours indicate the regions of charge gain and loss, respectively. Grey, white, blue, yellow and purple balls represent $\mathrm{C}, \mathrm{H}, \mathrm{N}, \mathrm{S}, \mathrm{Li}$ atoms, respectively. Reproduced with permission. ${ }^{140}$ Copyright 2015, Nature Publishing Group. Schematics of the LiPSs anchoring-diffusionconversion processes on the $\mathrm{N}-\mathrm{Co}_{9} \mathrm{~S}_{8}(\mathrm{e}), \mathrm{Co}_{9} \mathrm{~S}_{8}$ electrodes (f), and pure carbon paper (g). (h) Binding energy between LiPSs and matrix with (311) as well as (440) facets, respectively. (i) LiPSs adsorption ability of $\mathrm{N}-\mathrm{Co}_{9} \mathrm{~S}_{8}$ and $\mathrm{Co}_{9} \mathrm{~S}_{8}$ nanoparticles in the $\mathrm{Li}_{2} \mathrm{~S}_{6}$ solution. Reproduced with permission. ${ }^{157}$ Copyright 2020, Wiley-VCH.

confirmed that the doped $\mathrm{N}$ atom coupled with the $\mathrm{S}$ atom provides stronger binding energies for anchoring polysulfides than mono-doped (S or N) graphene (Fig. $7 \mathrm{~b}-\mathrm{d}$ ). Moreover, the $\mathrm{N}$, S-co-doped graphene conductive framework provides high electrical conductivity and rapid on-transport channels. Taken together, the N, S-co-doped graphene electrode with a high sulfur loading of $4.6 \mathrm{mg} \mathrm{cm} \mathrm{cm}^{-2}$ exhibits fast reaction dynamics, reduced polarization and stabilized cycling performance with only $0.078 \%$ capacity decay per cycle up to 500 cycles. Moreover, in Wang's work, a new boron/oxygen co-doped porous carbon (BOC) host material was successfully prepared by in situ organic condensation reaction on the exterior surface of CNTs for high-performance Li-S batteries. ${ }^{154}$ The interface of boron/oxygen co-doped carbon with hierarchical pore structure designed from the molecular scale can not only increase the electronic conductivity but also improves the sulfur activity and capture polysulfides/sulfur by producing thiosulfate and polythionate, which promotes electrochemical performance for Li-S batteries, including a large reversible capacity of $1077 \mathrm{~mA} \mathrm{~h} \mathrm{~g}^{-1}$ after 200 cycles at $0.2 \mathrm{C}$ and long cycling stability of $794 \mathrm{~mA} \mathrm{~h} \mathrm{~g}^{-1}$ at $1 \mathrm{C}$ after 500 cycles with only $0.07 \%$ attenuation per cycle. 
Recently, besides carbon matrix, non-metal atoms are also introduced in transition metal compounds (i.e., transition metal oxides and sulfides). ${ }^{155,156}$ Zhang et al. constructed nitrogen-doped $\mathrm{Co}_{9} \mathrm{~S}_{8}$ nanoparticles through the hydrothermal reactions for $\mathrm{Li}-\mathrm{S}$ batteries. ${ }^{157} \mathrm{Li}-\mathrm{N}$ bonds are more favorable than Li-S bonds when anchored on LiPSs in Li-S batteries, thus the notorious "shuttling effect" is inhibited by N-doped $\mathrm{Co}_{9} \mathrm{~S}_{8}$ nanoparticles (Fig. 7e-g), which has been verified by DFT calculations and LiPSs absorption experiments as shown in Fig. $7 \mathrm{~h}$ and i. Furthermore, introducing nitrogen atoms can improve the catalytic capabilities of $\mathrm{Co}_{9} \mathrm{~S}_{8}$ nanoparticles in $\mathrm{Li}-\mathrm{S}$ batteries. Consequently, $\mathrm{N}$-doped $\mathrm{Co}_{9} \mathrm{~S}_{8}$ nanoparticles provide a series of enhanced electrochemistry properties, such as a high reversible capacity $\left(1245 \mathrm{~mA} \mathrm{~h} \mathrm{~g}^{-1}\right.$ at $\left.0.2 \mathrm{~mA} \mathrm{~g}^{-1}\right)$, fast reaction kinetics (a record value of $604 \mathrm{~mA} \mathrm{~h} \mathrm{~g}^{-1}$ at $20 \mathrm{~A} \mathrm{~g}^{-1}$ ), and a low capacity decay of $0.037 \%$ /cycle over 1000 cycles. In addition, the surface acidity of $\mathrm{TiO}_{2}$ was tailored by $\mathrm{B}$ and $\mathrm{N}$ atoms to fortify the affinity between $\mathrm{TiO}_{2}$ and LiPSs. ${ }^{155}$
5.2 Metal atom-doping strategy. It is known that metal atoms provide strong catalytic properties, thus, introducing metal atoms into nanomaterials is supposed to be an effective means to accelerate the sluggish conversion kinetics of polysulfides in high-performance Li-S batteries. ${ }^{158}$ Since metal ions usually serve as the active sites to interact with polysulfides, optimizing their electronic and valence states is vital to enhance the catalytic activity, especially in sulfur redox reactions involving multiple electrons. ${ }^{159}$ In addition, the metal atomdoping strategy shows metallic characteristics and even superconductivity, ${ }^{\mathbf{1 6 0}}$ which is very beneficial to facilitate the redox reaction kinetics and increase the sulfur utilization efficiency for Li-S batteries. The single metal atom doped in carbon matrix is widely known as single-atom materials, which will be discussed separately in this review. Herein, we emphatically introduce metal atom doped in the non-carbon matrix in this topic.

For the heteroatom doped into the non-carbon matrix, some directly replace the original atom in the matrix, leading to a new
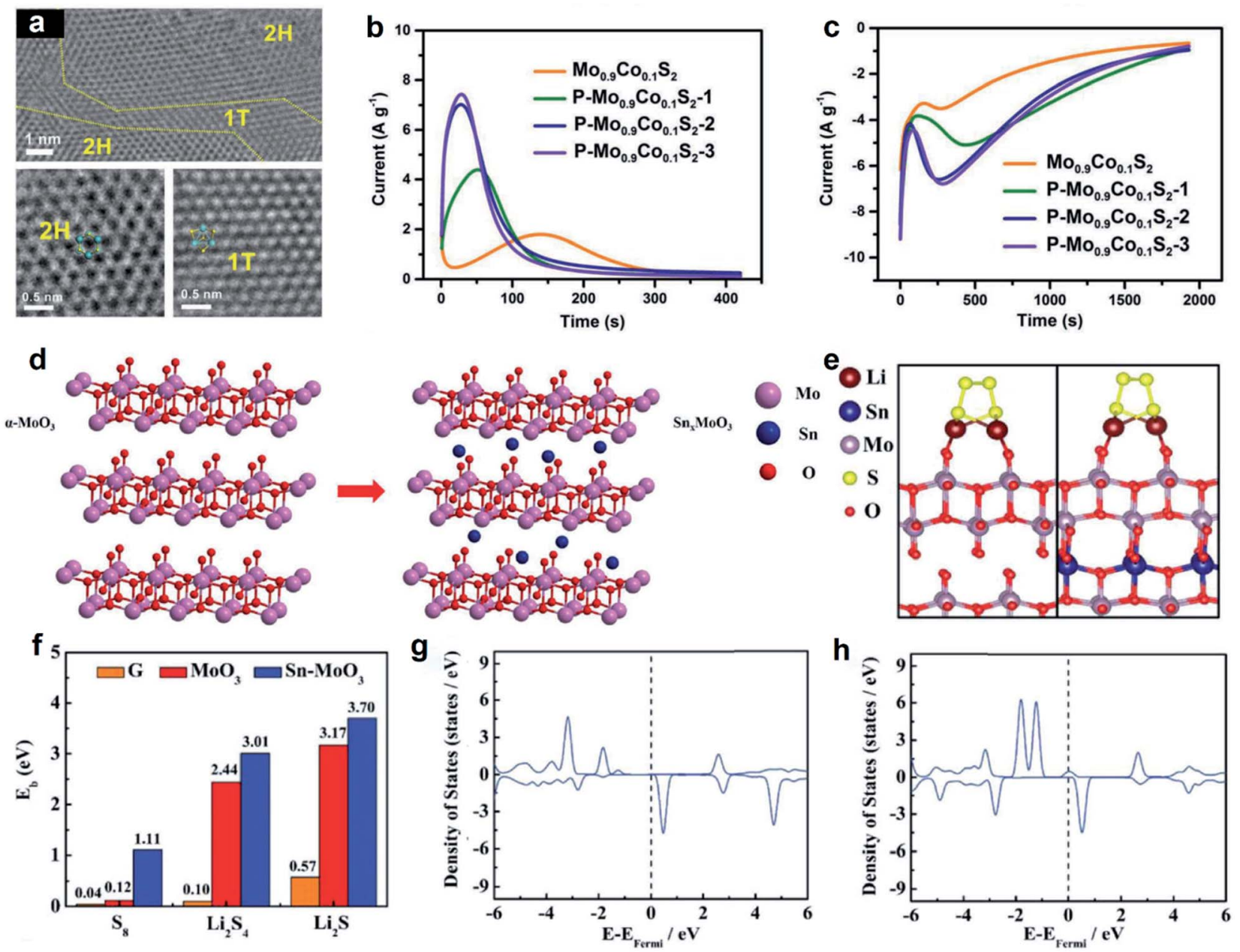

Fig. 8 (a) HRTEM images of $\mathrm{Mo}_{0.9} \mathrm{CO}_{0.1} \mathrm{~S}_{2}$. (b) Potentiostatic charging of variously doped $\mathrm{MoS}_{2}$ from the open circuit condition (2.2 V) to $2.4 \mathrm{~V}$ and (c) potentiostatic discharging to $2 \mathrm{~V}$. Reproduced with permission. ${ }^{162}$ Copyright 2019, Wiley-VCH. (d) Schematic illustration of intercalation process of $\mathrm{Sn}$ atoms into $\mathrm{MoO}_{3}$ nanoribbons. (e) Optimized adsorption configuration for $\mathrm{Li}_{2} \mathrm{~S}_{4}$ on $\mathrm{MoO}_{3}$ slab and $\mathrm{Sn}-\mathrm{MoO}_{3}$ slab, respectively. (f) Calculated binding strength for $\mathrm{S}_{8}, \mathrm{Li}_{2} \mathrm{~S}_{4}$, and $\mathrm{Li}_{2} \mathrm{~S}$ on graphene, $\mathrm{MoO}_{3}$ and $\mathrm{Sn}$ intercalated $\mathrm{MoO}_{3}$. DOS for $\mathrm{Li}_{2} \mathrm{~S}_{4}$ adsorbed on $\mathrm{MoO}_{3}(\mathrm{~g}$ ) and $\mathrm{Sn}-$ $\mathrm{MoO}_{3}$ slab (h), respectively. Reproduced with permission. ${ }^{164}$ Copyright 2018 , Wiley-VCH. 
phase. ${ }^{161}$ Lee et al. reported new cobalt and phosphorous codoped $\mathrm{MoS}_{2}$ for improved catalytic properties on LiPSs conversion in Li-S batteries. ${ }^{162}$ First, by introducing cobalt atoms in $\mathrm{MoS}_{2}$, the semiconductor $2 \mathrm{H}$ phase of $\mathrm{MoS}_{2}$ with common honeycomb lattice geometry (trigonal prismatic coordination) is transformed to metallic $1 \mathrm{~T}$ phase with trigonal lattice geometry (octahedral coordination), which promotes the electrical conductivity of $\mathrm{MoS}_{2}$ (Fig. 8a). Furthermore, partial sulfur atoms exposed on the surface of $\mathrm{MoS}_{2}$ were replaced by phosphorous atoms, in which the lone-pair electrons in the $3 \mathrm{p}$ orbitals and vacant $3 \mathrm{~d}$ orbitals cause an increasing local electron density, resulting in a high activity in polysulfide conversion reactions. All these advantages for LiPSs conversion were also verified via the current-time responses from potentiostatic charging $\left(\mathrm{Li}_{2} \mathrm{~S}_{6}\right.$ oxidation) and potentiostatic discharging $\left(\mathrm{Li}_{2} \mathrm{~S}_{6}\right.$ reduction) of lithium-catalyst cells, corresponding to the polysulfide oxidation and reduction currents increased significantly after phosphorus doping (Fig. $8 \mathrm{~b}$ and c). Consequently, a sulfur cathode with $\mathrm{P}-\mathrm{Mo}_{0.9} \mathrm{Co}_{0.1} \mathrm{~S}_{2}-2$ exhibits a low capacity fade rate of $0.046 \%$ per cycle (over 600 cycles at $1 \mathrm{C}$ rate).

Besides replacing the original atom in the matrix, some heteroatoms insert into the structure gap in the matrix. ${ }^{\mathbf{1 6 3}}$ Zhang et al. successfully inserted tin atoms into van der Waals' gap of 2D layered $\alpha-\mathrm{MoO}_{3}$ (Fig. 8d), resulting in enhancing the intrinsic the conductivity of $\mathrm{MoO}_{3}{ }^{164}$ Moreover, the DFT calculation demonstrated that the binding energy with sulfur species was enhanced after the insertion of $\mathrm{Sn}$ atoms. This can be attributed to abundant electrons of the intercalated $\mathrm{Sn}$ atoms, which were filled in the conduction bands of $\mathrm{MoO}_{3}$ and further tuned the electronic structures (Fig. 8e and f). In addition, after absorbing $\mathrm{Li}_{2} \mathrm{~S}_{4}$ on Sn-doped $\mathrm{MoO}_{3}$, the lower state electrons transferred into upper levels, which is near the Fermi

Table 4 Electrochemical performance for Li-S batteries with single-atom catalysts

\begin{tabular}{|c|c|c|c|c|c|}
\hline \multirow[b]{2}{*}{ Catalysis } & \multirow[b]{2}{*}{$\begin{array}{l}\text { Sulfur loading } \\
\left(\mathrm{mg} \mathrm{cm}^{-2}\right)\end{array}$} & \multirow[b]{2}{*}{$\begin{array}{l}\text { Redox } \\
\text { intermediate }\end{array}$} & \multicolumn{2}{|l|}{ Performance } & \multirow[b]{2}{*}{ Ref } \\
\hline & & & $\begin{array}{l}\text { Special capacity } \\
\left(\mathrm{mA} \mathrm{h}^{-1}\right)\end{array}$ & Cycling stability & \\
\hline Fe-N/MHCS & 5.4 & LiPSs & 1097 at $0.1 \mathrm{C}$ & $\begin{array}{l}1000 \text { cycles (decay rate of } 0.018 \% / \text { cycle at } \\
\text { 1C) }\end{array}$ & 180 \\
\hline $\mathrm{SAFe} @ g-\mathrm{C}_{3} \mathrm{~N}_{4}$ & 2.3 & LiPSs & 1379 at $0.1 \mathrm{C}$ & $\begin{array}{l}200 \text { cycles (decay rate of } 0.05 \% / \text { cycle at } \\
0.2 \mathrm{C} \text { ) }\end{array}$ & 192 \\
\hline FeSA-CN & 1.4 & LiPSs & 1123 at $0.2 \mathrm{C}$ & $\begin{array}{l}500 \text { cycles (decay rate of } 0.06 \% / \text { cycle at } \\
4 \text { C) }\end{array}$ & 188 \\
\hline Fe-PNC & 1.3 & LiPSs & 1138.6 at $0.1 \mathrm{C}$ & $\begin{array}{l}300 \text { cycles (decay rate of } 0.2 \% / \text { cycle at } \\
0.1 \mathrm{C} \text { ) }\end{array}$ & 193 \\
\hline Fe@NG & 1.1 & LiPSs & 1616 at $0.1 \mathrm{C}$ & $\begin{array}{l}200 \text { cycles (decay rate of } 0.15 \% / \text { cycle at } \\
\text { 2C) }\end{array}$ & 194 \\
\hline NC:SAFe & - & LiPSs & 1052 at $1 \mathrm{C}$ & $\begin{array}{l}1000 \text { cycles (decay rate of } 0.06 \% / \text { cycle at } \\
\text { 5C) }\end{array}$ & 195 \\
\hline $\mathrm{Fe} / \mathrm{NG}$ & 4.5 & LiPSs & 1000 at $0.5 \mathrm{C}$ & $\begin{array}{l}750 \text { cycles (decay rate of } 0.022 \% / \text { cycle at } \\
0.5 \mathrm{C} \text { ) }\end{array}$ & 196 \\
\hline FeNSC & 1 & LiPSs & 550.2 at $4 \mathrm{C}$ & $\begin{array}{l}1000 \text { cycles (decay rate of } 0.047 \% / \text { cycle at } \\
\text { 1C) }\end{array}$ & 189 \\
\hline Co-N/G & 6 & LiPSs & 1210 at $0.2 \mathrm{C}$ & $\begin{array}{l}100 \text { cycles (decay rate of } 0.029 \% / \text { cycle at } \\
0.2 \mathrm{C} \text { ) }\end{array}$ & 185 \\
\hline CoSA-N-C & 4.9 & Thiosulfate & 1574 at $0.05 \mathrm{C}$ & $\begin{array}{l}120 \text { cycles (decay rate of } 0.068 \% / \text { cycle at } \\
0.2 \mathrm{C} \text { ) }\end{array}$ & 186 \\
\hline 2D NC@SA-Co & 7.2 & LiPSs & 1160 at $0.1 \mathrm{C}$ & $\begin{array}{l}700 \text { cycles (decay rate of } 0.058 \% / \text { cycle at } \\
\text { 2C) }\end{array}$ & 184 \\
\hline B/2D MOF-Co & 7.8 & LiPSs & 921 at $0.1 \mathrm{C}$ & $\begin{array}{l}600 \text { cycles (decay rate of } 0.07 \% / \text { cycle at } \\
1 \mathrm{C} \text { ) }\end{array}$ & 182 \\
\hline $\mathrm{Co} @ \mathrm{C}_{3} \mathrm{~N}_{4}$ & 2 & LiPSs & 1400 at $1.6 \mathrm{~mA} \mathrm{~cm}^{-2}$ & $\begin{array}{l}200 \text { cycles (decay rate of } 0.09 \% / \text { cycle at } \\
1.6 \mathrm{~mA} \mathrm{~cm}^{-2} \text { ) }\end{array}$ & 197 \\
\hline C:SACo & - & LiPSs & 441 at $10 \mathrm{C}$ & $\begin{array}{l}1500 \text { cycles (decay rate of } 0.04 \% / \text { cycle at } \\
2 \mathrm{C} \text { ) }\end{array}$ & 198 \\
\hline Ni@NG & 6 & LiPSs & 1598 at $0.1 \mathrm{C}$ & $\begin{array}{l}500 \text { cycles (decay rate of } 0.06 \% / \text { cycle at } \\
10 \mathrm{C} \text { ) }\end{array}$ & 187 \\
\hline $\mathrm{ZnS}, \mathrm{Co}-\mathrm{N}-\mathrm{C}$ & 6 & LiPSs & 800 at $200 \mathrm{~mA} \mathrm{~g}^{-1}$ & $\begin{array}{l}100 \text { cycles (decay rate of } 0.077 \% / \text { cycle at } \\
0.6 \mathrm{C} \text { ) }\end{array}$ & 199 \\
\hline $\mathrm{Zn}_{1}-\mathrm{HNC}$ & 7.8 & LiPSs & 989 at $10 \mathrm{C}$ & $\begin{array}{l}700 \text { cycles (decay rate of } 0.015 \% / \text { cycle at } \\
10 \mathrm{C} \text { ) }\end{array}$ & 200 \\
\hline S@Mn/C-(N, O) & 4 & Thiosulfate & 900 at $1 \mathrm{C}$ & $\begin{array}{l}1000 \text { cycles (decay rate of } 0.05 \% / \text { cycle at } \\
1 \mathrm{C})\end{array}$ & 201 \\
\hline SA-Zn-MXene & 5.3 & LiPSs & 1136 at $0.2 \mathrm{C}$ & $\begin{array}{l}400 \text { cycles (decay rate of } 0.03 \% / \text { cycle at } \\
\text { 1C) }\end{array}$ & 191 \\
\hline
\end{tabular}


level and easier to get involved in reactions, thus propel the redox of $\mathrm{Li}_{2} \mathrm{~S}_{4}$ and promoting the electrochemical performance (Fig. $8 \mathrm{~g}$ and $\mathrm{h}$ ).

\section{Single atoms catalysts}

Single atoms (SAs) catalysts, which refer to single metal atoms anchored by surrounding coordination species (M-N $\mathrm{N}_{x}$ species), are proposed to obtain the maximum utilization and catalytic activity at the atomic level. ${ }^{178-180}$ SAs catalysts with tunable local environments can be precisely engineered and synthesized for optimal catalytic performance. ${ }^{181}$ In addition, SAs catalysts showcase great potential to elucidate the relationship between their structures and catalytic activity, as well as the mechanism of catalysis at the molecular level. Recently, SAs catalysts with unique atomic structures have been introduced in $\mathrm{Li}-\mathrm{S}$ batteries, which exhibit excellent performance in catalytic conversion of LiPSs and the suppression of lithium dendrite growth. ${ }^{179,182,183}$ Currently, the application of SAs catalysts in $\mathrm{Li}-$ $S$ batteries is still in the primary stage, and the reported metal atoms in single-atom moieties mainly include iron, cobalt, nickel, zinc, copper, etc. According to different matrixes, SAs catalysts are divided into carbon-based catalysts and noncarbon-based single-atom catalysts in this review. Table 4 shows the electrochemical properties of $\mathrm{Li}-\mathrm{S}$ batteries with single-atom catalysts.

6.1 Carbon-based single atoms catalysts. Currently, carbon materials (i.e., graphene, $\mathrm{CNT}, \mathrm{CNF}, \mathrm{g}-\mathrm{C}_{3} \mathrm{~N}_{4}$, hollow carbon sphere, porous carbon) have been regarded as common SA matrices due to their high electric conductivity, which could provide a favorable environment for electron transfer in sulfur redox reactions. In addition, on account of the controllable structures and components, the carbon matrix could offer abundant coordinate sites and various coordination atoms, leading to a high loading mass of metal atoms and stable SAs
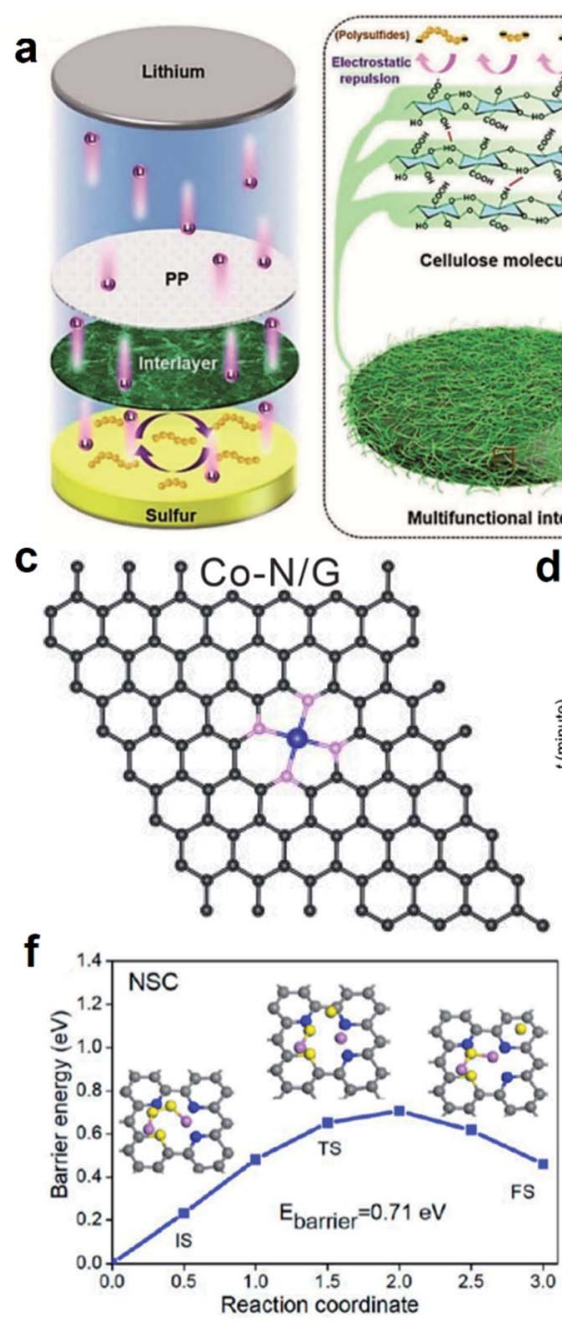
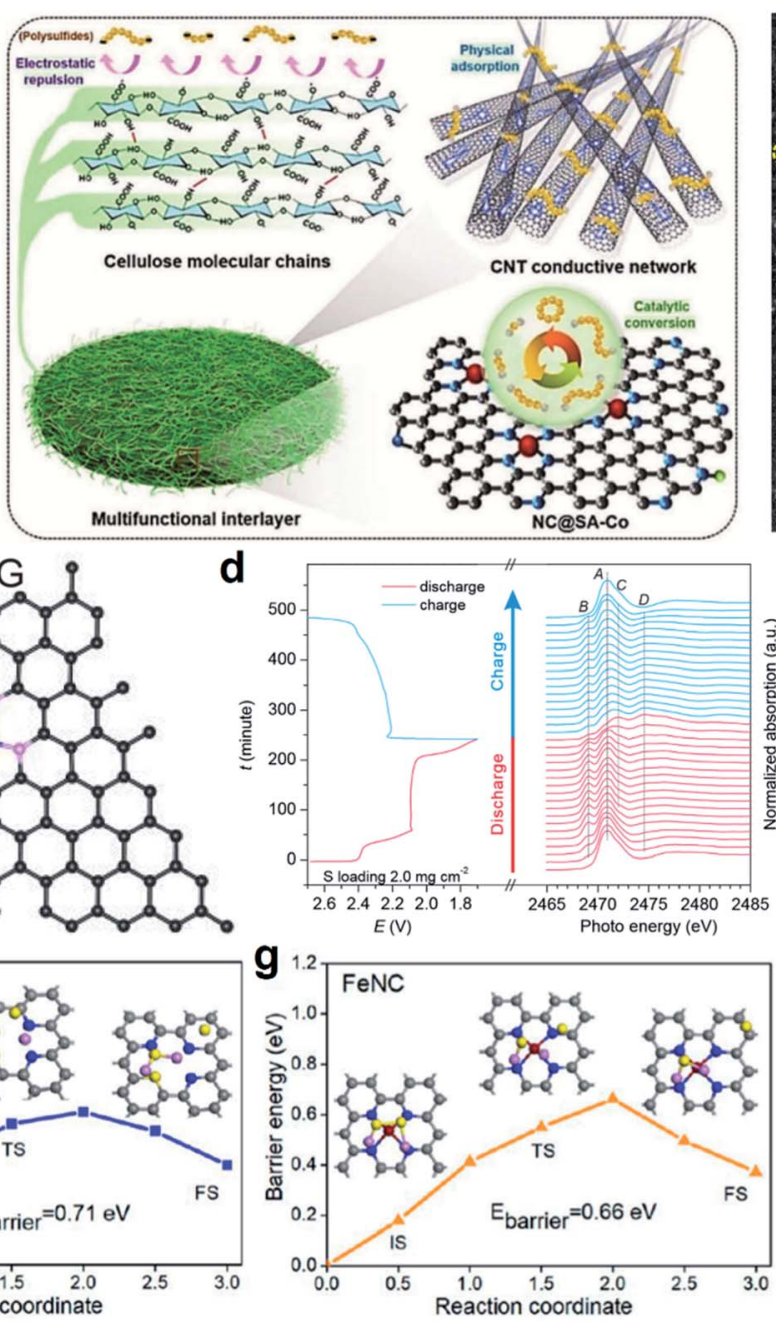
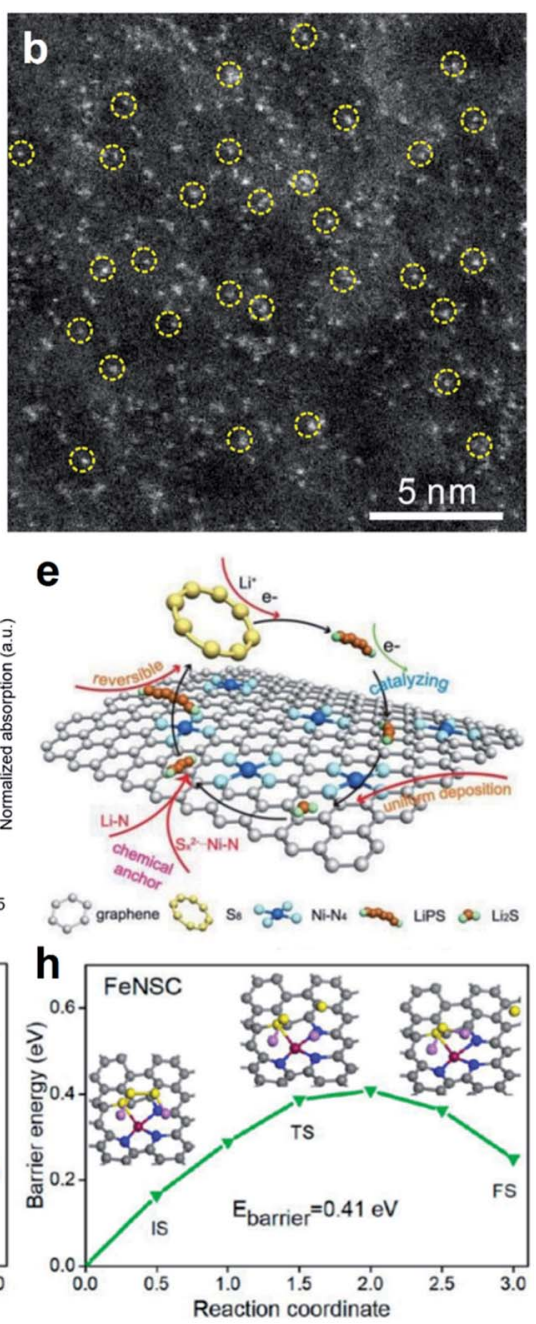

Fig. 9 (a) Illustration of the multifunctional interlayer of NCASA-Co and CNT-CNF. Reproduced with permission. ${ }^{184}$ Copyright 2020 , Wiley-VCH. (b) HAADF-STEM images of Co-N/G. (c) Structures of Co-N/G used in DFT calculations. (d) Evolution of S K-edge XANS during electrochemical cycling. Reproduced with permission. ${ }^{185}$ Copyright 2019, American Chemical Society. (e) The catalytic mechanism of the LiPSs on the surface of $\mathrm{NiaNG}$ in the electrochemical process. Reproduced with permission. ${ }^{187}$ Copyright 2019, Wiley-VCH. Energy profiles of Li $\mathrm{S}_{2}$ decomposition on NSC (f), FeNC (g), and FeNSC (h) (insets are the initial, transition, and final structures). Reproduced with permission. ${ }^{189}$ Copyright 2021 , American Chemical Society. 
structure. Therefore, SAs combined with electronic conductivity carbon have been proposed to be a promising way for advanced Li-S batteries.

Guo and co-workers designed single-atom cobalt-anchored nitrogen-doped carbon nanosheets (NC@SA-Co) and the dual network of carbon nanotube-cellulose nanofiber (CNT-CNF) hybrid as an interlayer for Li-S batteries (Fig. 9a). ${ }^{184}$ Notably, numerous well-defined single sites of Co- $\mathrm{N}_{4}$ in the NC@SA-Co structure accelerate the liquid-liquid conversion of LiPSs. As a result, the Li-S battery with this interlayer exhibits a high reversible specific capacity of $1160 \mathrm{~mA} \mathrm{~h} \mathrm{~g}^{-1}$ at $0.1 \mathrm{C}$, and an ultralow capacity decay of $0.058 \%$ per cycle over 700 cycles. In addition, Wan et al. proposed an experimental case of a Co single atoms catalyst as a sulfur host in Li-S batteries, which had a significant impact on the development of highperformance $\mathrm{Li}-\mathrm{S}$ batteries and other electrochemical energy storage devices. ${ }^{185}$ As shown in Fig. 9b, the monodispersed Co atoms were embedded in the lattice of $\mathrm{N}$-doped graphene (Co-N/ $\mathrm{G})$, in which Co atoms coordinated with $\mathrm{N}$ atoms to form $\mathrm{Co}-\mathrm{N}_{4}$ coordination centers. The results of DFT calculation (Fig. 9c) and operando X-ray absorption spectroscopy (Fig. 9d) indicated that the Co- $\mathrm{N}_{4}$ coordination center can be used as a bifunctional electrocatalyst, which can promote the formation and decomposition of $\mathrm{Li}_{2} \mathrm{~S}_{x}$ during discharging and charging process. Subsequently, Co-N/G exhibits high utilization of sulfur at an ultrahigh sulfur mass ratio (90 wt\%), resulting in a gravimetric capacity of $1210 \mathrm{~mA} \mathrm{~h} \mathrm{~g}^{-1}$ and only the capacity decay rate of $0.029 \%$ over 100 cycles. Furthermore, Sun and coworkers confirmed that $\mathrm{Co}-\mathrm{N}_{4}$ active sites can oxidize LiPSs to thiosulfate with a surface redox reaction between sulfur host and LiPSs. ${ }^{186}$ Similarly, Niu et al. reported that high-density single $\mathrm{Ni}$ atoms could be embedded in $\mathrm{N}$-doped graphene matrix (Ni@NG) by pyrolysis approach. ${ }^{187}$ They found that the oxidized $\mathrm{Ni}$ sites in $\mathrm{Ni}-\mathrm{N}_{4}$ structure can accommodate the electrons of polysulfide ions by forming strong $\mathrm{S} 2-\mathrm{X} \cdots \mathrm{Ni}-\mathrm{N}$ bonding, which could decline the energy barrier required for the Li-S bond decomposition (Fig. 9e), and thus enhance the dynamic transformation of LiPSs in Li-S batteries effectively.

Based on a large special surface area, porous carbon-based single-atom catalyst not only could accelerate the LiPSs conversion but also promote the chemical adsorption process of LiPSs; meanwhile, inhibit the shuttle effect of polysulfide. Liu et al. proposed a MOF-derived Fe-SA catalyst (FeSA-CN) as a sulfur host for stable and efficient Li-S batteries. ${ }^{188}$ It has been verified that FeSA-CN can promote the chemical adsorption of LiPSs, inhibit the shuttle effect of LiPSs, achieve effective $\mathrm{Li}^{+} / \mathrm{e}^{-}$ transfer and accelerate the redox reaction. As a result, even under high charge and discharge rate conditions, the capacity of the FeSA-CN/S electrode was still maintained as high as $70 \%$ after 500 cycles of 4.0C. Chen $e t$ al. proposed a Fe single atom located on N-doped mesoporous hollow carbon spheres $(\mathrm{N} /$ MHCS), which could remarkably alleviate the shuttle effect. ${ }^{180}$ Furthermore, Li and co-workers introducing sulfur atoms into the $\mathrm{Fe}-\mathrm{N}_{4}$ coordination center for modulating the electronic structure of the Fe atom in coordination active sites. ${ }^{189}$ Interestingly, the $\mathrm{Fe}-\mathrm{N}_{3} \mathrm{~S}$ active site exhibits the lowest energy barrier than that of N, S active sites, and $\mathrm{Fe}-\mathrm{N}_{4}$ active site (Fig. $9 \mathrm{f}-\mathrm{h}$ ),
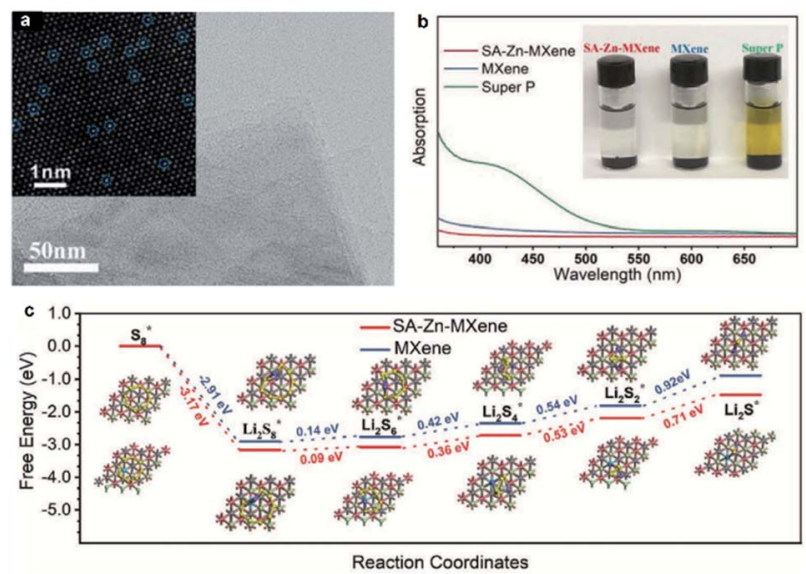

Fig. 10 (a) The HAADF-STEM images of SA-Zn-MXene. (b) Visual adsorption tests of $\mathrm{SA}-\mathrm{Zn}-\mathrm{MXene}, \mathrm{MXene}$, and super $\mathrm{P}$ with their corresponding UV/vis spectra. (c) The Gibbs free energy profiles of LiPSs on SA-Zn-MXene and MXene. Reproduced with permission. ${ }^{179}$ Copyright 2020, Wiley-VCH.

thus the S-doped Fe single-atom catalyst can dramatically promote the LiPSs redox rate and exhibit $0.047 \%$ capacity decay per cycle over 1000 cycles at $1 \mathrm{C}$.

6.2 Non-carbon-based single atoms catalysts. The noncarbon material used as the matrix of single atoms should possess high conductivity properties and active surface with ample unsaturated bonds, so the available options are really fewer, especially for the metal compound. At present, limited research works are focused on non-carbon-based single-atom catalysts for Li-S batteries. Mxene, which can provide more ions transport channels, large volume and area capacitance, has been regarded as a potential non-carbon matrix. ${ }^{190}$ The unique properties of MXenes immobilized by single-atom metal can greatly promote the redox reaction of LiPSs, resulting in the promoted the electrochemical performance of Li-S batteries.

Yang et al. designed a single $\mathrm{Zn}$ atom doped MXene layer (SAZn-MXene) (Fig. 10a). ${ }^{191}$ As a sulfur cathode, SA-Zn-MXene realizes the strong interaction with LiPSs due to the high electronegativity of atomic zinc on MXene (Fig. 10b). Furthermore, as shown in Fig. 10c, the conversion of LiPSs can be effectively facilitated by reducing the energy barrier from $\mathrm{Li}_{2} \mathrm{~S}_{4}$ to $\mathrm{Li}_{2} \mathrm{~S}_{2} /$ $\mathrm{Li}_{2} \mathrm{~S}$. Moreover, the SA-Zn-MXene layer can effectively promote nucleation of solid-state $\mathrm{Li}_{2} \mathrm{~S}_{2}$ and $\mathrm{Li}_{2} \mathrm{~S}$ on their large-scale exposed 2D surface. Taken together, SA-Zn-MXene cathode

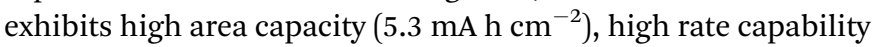
( $640 \mathrm{~mA} \mathrm{~h} \mathrm{~g}^{-1}$ at $6 \mathrm{C}$ ), and good cycle stability with $80 \%$ capacity retention after 200 cycles at $4 \mathrm{C}$.

\section{Conclusions and outlook}

For Li-S batteries, LiPSs shuttling in an electrolyte between the cathode and anode could corrode the lithium anode, which is considered to be the main reason for capacity fading. Thus, an ideal cathode material is required to possess not only high conductivity and high sulfur-loading mass but also a strong 
affinity for LiPSs and the ability to propel LiPSs conversion, which is expected as one of the most feasible methods for suppressing LiPSs diffusion. In this aspect, catalytic materials including catalytic metal-based materials (metals and their oxides, sulfides, nitrides) and some metal-free materials with catalytic activities are considered the optimal sulfur host, which could offer abundant polar active sites for LiPS absorption and conversion overwhelmingly. At the current stage, plenty of novel catalytic materials have been rationally designed and constructed based on surface engineering in order to enhance the affinity for LiPSs and facilitate LiPS conversion in state-of-theart energy storage devices. To further enhance the sulfur reaction kinetics and promote the overall performance, there is a lot of room for investigations in sulfur host design.

(1) Generally, sulfur hosts were designed as hollow or porous structures with large specific surface areas, which could expose plentiful electrochemical active sites and supply ample spaces for sulfur volume explosion. Nonetheless, recent studies have demonstrated that a large specific area correlates with low cathode density and thus low volumetric energy density. ${ }^{202}$ Furthermore, cathodes with a large specific area should need more electrolytes to be wet, which also compromises the fullcell gravimetric energy density. ${ }^{203}$ Thus, cathode design strategy should strike a balance between the specific area of sulfur host and energy density of Li-S batteries.

(2) High sulfur loading of cathode causes high LiPSs concentration in electrolyte, resulting in severe corrosion to the lithium anode. Moreover, the lean electrolyte is easily to be consumed by reactive lithium and thus leads to battery failure. Therefore, the shuttling effect is more serious in lean electrolytes and high sulfur loading. It is necessary to evaluate all advanced materials for suppressing LiPSs shuttle under high cathode loading and lean electrolyte.

(3) Introducing deficiency into heterostructure or decorating heteroatoms in single atom moieties could deliver a synergistic effect for strengthening the adsorption and catalytic on LiPSs. Therefore, the combination of multiple surface engineering strategies may point an inspiring new direction for developing novel materials, which could alleviate LiPSs shuttling and improve the stability of Li-S cathode.

(4) Advanced in situ characterization techniques used in Li-S batteries provide deep, atomic-level mechanistic insights into the battery chemistry and reveal the nature of catalysts in their strong interactions with LiPSs, which will guide us to design better $\mathrm{Li}-\mathrm{S}$ batteries.

(5) Apart from the sulfur cathode, the commercial separator with catalytic interlayer could also facilitate the LiPSs conversion in an electrolyte. Moreover, functional anode materials could regulate $\mathrm{Li}$ nucleation and guide $\mathrm{Li}$ metal deposition. Thus, reasonable designing and modulation of the structure of interlayer and anode materials could deliver high energy density and stable cycling properties for Li-S batteries.

\section{Conflicts of interest}

There are no conflicts to declare.

\section{Acknowledgements}

This work was supported by the National Natural Science Foundation of China (51908256), the Natural Science Foundation of the Jiangsu Higher Education Institutions of China (19KJA460004), the Priority Academic Program Development of Jiangsu Higher Education Institutions.

\section{Notes and references}

1 H.-J. Peng, J.-Q. Huang and Q. Zhang, Chem. Soc. Rev., 2017, 46, 5237-5288.

2 H. Hu, B. Zhao, H. Cheng, S. Dai, N. Kane, Y. Yu and M. Liu, Nano Energy, 2019, 57, 635-643.

3 M. Park, J. Ryu, W. Wang and J. Cho, Nat. Rev. Mater., 2016, 2, 16080.

4 S.-H. Chung, C.-H. Chang and A. Manthiram, Adv. Funct. Mater., 2018, 28, 1801188.

5 A. Shyamsunder, W. Beichel, P. Klose, Q. Pang, H. Scherer, A. Hoffmann, G. K. Murphy, I. Krossing and L. F. Nazar, Angew. Chem., Int. Ed., 2017, 56, 6192-6197.

6 M. Cuisinier, P. E. Cabelguen, B. D. Adams, A. Garsuch, M. Balasubramanian and L. F. Nazar, Energy Environ. Sci., 2014, 7, 2697-2705.

7 Y. Yan, P. Zhang, Z. Qu, M. Tong, S. Zhao, Z. Li, M. Liu and Z. Lin, Nano Lett., 2020, 20, 7662-7669.

8 H.-J. Peng, J.-Q. Huang, X.-B. Cheng and Q. Zhang, Adv. Energy Mater., 2017, 7, 1700260.

9 M. Rana, S. A. Ahad, M. Li, B. Luo, L. Wang, I. Gentle and R. Knibbe, Energy Storage Mater., 2019, 18, 289-310.

10 H. Dai, B. Yuan, C. Bai, C. Lai and C. Wang, J. Electrochem. Soc., 2018, 165, A2866-A2868.

11 H. Hu, Y. Hu, H. Cheng, S. Dai, K. Song and M. Liu, J. Power Sources, 2021, 491, 229617.

12 M. Zhang, W. Chen, L. Xue, Y. Jiao, T. Lei, J. Chu, J. Huang, C. Gong, C. Yan, Y. Yan, Y. Hu, X. Wang and J. Xiong, Adv. Energy Mater., 2020, 10, 1903008.

13 D. Liu, C. Zhang, G. Zhou, W. Lv, G. Ling, L. Zhi and Q.-H. Yang, Adv. Sci., 2018, 5, 1700270.

14 Z. Su, C.-J. Tong, D.-Q. He, C. Lai, L.-M. Liu, C. Wang and K. Xi, J. Mater. Chem. A, 2016, 4, 8541-8547.

15 Q. Feng, X. Zhao, Y. Guo, M. Liu and P. Wang, Biosens. Bioelectron., 2018, 108, 97-102.

16 M. Liu, P. Zhang, Z. Qu, Y. Yan, C. Lai, T. Liu and S. Zhang, Nat. Commun., 2019, 10, 3917.

17 B. Dou, J. Yan, Q. Chen, X. Han, Q. Feng, X. Miao and P. Wang, Sens. Actuators, B, 2021, 328, 129082.

18 F. Liu, Y. Cheng, J. Tan, J. Li, H. Cheng, H. Hu, C. Du, S. Zhao, Y. Yan and M. Liu, Front. Chem., 2021, 9, 668336.

19 L. Sun, X. He, S. Zeng, Y. Yuan, R. Li, W. Zhan, J. Chen, X. Wang and X. Han, Inorg. Chem., 2021, 60, 1160-1171.

20 W. Zhan, Y. Yuan, L. Sun, Y. Yuan, X. Han and Y. Zhao, Small, 2019, 15, 1901024.

21 M. Liu, Y. Liu, Y. Yan, F. Wang, J. Liu and T. Liu, Chem. Commun., 2017, 53, 9097-9100.

22 M. Liu, Z. Yang, H. Sun, C. Lai, X. Zhao, H. Peng and T. Liu, Nano Res., 2016, 9, 3735-3746. 
23 L. Kong, J.-X. Chen, H.-J. Peng, J.-Q. Huang, W. Zhu, Q. Jin, B.-Q. Li, X.-T. Zhang and Q. Zhang, Energy Environ. Sci., 2019, 12, 2976-2982.

24 Y. Tao, Y. Wei, Y. Liu, J. Wang, W. Qiao, L. Ling and D. Long, Energy Environ. Sci., 2016, 9, 3230-3239.

25 H. Zhang, M. Zou, W. Zhao, Y. Wang, Y. Chen, Y. Wu, L. Dai and A. Cao, ACS Nano, 2019, 13, 3982-3991.

26 Y. Zhong, L. Yin, P. He, W. Liu, Z. Wu and H. Wang, J. Am. Chem. Soc., 2018, 140, 1455-1459.

27 Q. Pang, C. Y. Kwok, D. Kundu, X. Liang and L. F. Nazar, Joule, 2019, 3, 136-148.

28 X. Wu, N. Liu, M. Wang, Y. Qiu, B. Guan, D. Tian, Z. Guo, L. Fan and N. Zhang, ACS Nano, 2019, 13, 13109-13115.

29 L. Ni, Z. Wu, G. Zhao, C. Sun, C. Zhou, X. Gong and G. Diao, Small, 2017, 13, 1603466.

30 X. Liu, T. Kong, J. Qu, C. Wang and C. Lai, J. Electrochem. Soc., 2019, 166, A3886-A3888.

31 T.-Z. Hou, X. Chen, H.-J. Peng, J.-Q. Huang, B.-Q. Li, Q. Zhang and B. Li, Small, 2016, 12, 3283-3291.

32 C. Ye, Y. Jiao, D. Chao, T. Ling, J. Shan, B. Zhang, Q. Gu, K. Davey, H. Wang and S.-Z. Qiao, Adv. Mater., 2020, 32, 1907557.

33 M. Wild, L. O'Neill, T. Zhang, R. Purkayastha, G. Minton, M. Marinescu and G. J. Offer, Energy Environ. Sci., 2015, 8, 3477-3494.

34 H. Wang, W. Zhang, J. Xu and Z. Guo, Adv. Funct. Mater., 2018, 28, 1707520.

35 X. Liu, J.-Q. Huang, Q. Zhang and L. Mai, Adv. Mater., 2017, 29, 1601759.

36 M. Zhao, H.-J. Peng, B.-Q. Li, X. Chen, J. Xie, X. Liu, Q. Zhang and J.-Q. Huang, Angew. Chem., Int. Ed., 2020, 59, 9011-9017.

37 D. Moy, A. Manivannan and S. R. Narayanan, J. Electrochem. Soc., 2014, 162, A1-A7.

38 R. S. Assary, L. A. Curtiss and J. S. Moore, J. Phys. Chem. C, 2014, 118, 11545-11558.

39 C. Barchasz, F. Molton, C. Duboc, J.-C. Leprêtre, S. Patoux and F. Alloin, Anal. Chem., 2012, 84, 3973-3980.

40 X. Liang, C. Y. Kwok, F. Lodi-Marzano, Q. Pang, M. Cuisinier, H. Huang, C. J. Hart, D. Houtarde, K. Kaup, H. Sommer, T. Brezesinski, J. Janek and L. F. Nazar, Adv. Energy Mater., 2016, 6, 1501636.

41 S. Tan, Y. Dai, Y. Jiang, Q. Wei, G. Zhang, F. Xiong, X. Zhu, Z.-Y. Hu, L. Zhou, Y. Jin, K. Kanamura, Q. An and L. Mai, Adv. Funct. Mater., 2021, 31, 2008034.

42 S. Chen, J. Luo, N. Li, X. Han, J. Wang, Q. Deng, Z. Zeng and S. Deng, Energy Storage Mater., 2020, 30, 187-195.

43 S. Gu, Z. Bai, S. Majumder, B. Huang and G. Chen, Nanoscale, 2019, 11, 20579-20588.

44 Q. Wang, W. Zhang, C. Guo, Y. Liu, C. Wang and Z. Guo, Adv. Funct. Mater., 2017, 27, 1703390.

45 Y. Yang, L. Sun, W. Zhan, X. Wang and X. Han, J. Mater. Chem. A, 2021, 9, 4310-4316.

46 H. Liu, Z. Chen, L. Zhou, K. Pei, P. Xu, L. Xin, Q. Zeng, J. Zhang, R. Wu, F. Fang, R. Che and D. Sun, Adv. Energy Mater., 2019, 9, 1901667.
47 L. Jiao, C. Zhang, C. Geng, S. Wu, H. Li, W. Lv, Y. Tao, Z. Chen, G. Zhou, J. Li, G. Ling, Y. Wan and Q.-H. Yang, Adv. Energy Mater., 2019, 9, 1900219.

48 L. Sun, Y. Zhuang, Y. Yuan, W. Zhan, X.-J. Wang, X. Han and Y. Zhao, Adv. Energy Mater., 2019, 9, 1902839.

49 C. Zhang, S. Liu, G. Li, C. Zhang, X. Liu and J. Luo, Adv. Mater., 2018, 30, 1801328.

50 H. Li, Q. Jin, J. Zhao, B. Wang and X. Guo, Dalton Trans., 2020, 49, 12686-12694.

51 S. Huang, Z. Wang, Y. Von Lim, Y. Wang, Y. Li, D. Zhang and H. Y. Yang, Adv. Energy Mater., 2021, 11, 2003689.

52 Y.-S. Su and A. Manthiram, J. Power Sources, 2014, 270, 101105.

53 G. Zhou, H. Tian, Y. Jin, X. Tao, B. Liu, R. Zhang, Z. W. Seh, D. Zhuo, Y. Liu, J. Sun, J. Zhao, C. Zu, D. S. Wu, Q. Zhang and Y. Cui, Proc. Natl. Acad. Sci. U. S. A., 2017, 114, 840.

54 L. Ma, S. Wei, H. L. Zhuang, K. E. Hendrickson, R. G. Hennig and L. A. Archer, J. Mater. Chem. A, 2015, 3, 19857-19866.

55 J. He, G. Hartmann, M. Lee, G. S. Hwang, Y. Chen and A. Manthiram, Energy Environ. Sci., 2019, 12, 344-350.

56 K. Chang, D. Geng, X. Li, J. Yang, Y. Tang, M. Cai, R. Li and X. Sun, Adv. Energy Mater., 2013, 3, 839-844.

57 Y. Li, H. Wang, L. Xie, Y. Liang, G. Hong and H. Dai, J. Am. Chem. Soc., 2011, 133, 7296-7299.

58 J. He, P. Li, W. Lv, K. Wen, Y. Chen, W. Zhang, Y. Li, W. Qin and W. He, Electrochim. Acta, 2016, 215, 12-18.

59 P. Guo, K. Sun, X. Shang, D. Liu, Y. Wang, Q. Liu, Y. Fu and D. He, Small, 2019, 15, 1902363.

60 S. Yao, J. Cui, J.-Q. Huang, Z. Lu, Y. Deng, W. G. Chong, J. Wu, M. Ihsan Ul Haq, F. Ciucci and J.-K. Kim, Adv. Energy Mater., 2018, 8, 1800710.

61 H. Yuan, H.-J. Peng, B.-Q. Li, J. Xie, L. Kong, M. Zhao, X. Chen, J.-Q. Huang and Q. Zhang, Adv. Energy Mater., 2019, 9, 1802768.

62 W. Tian, B. Xi, Z. Feng, H. Li, J. Feng and S. Xiong, Adv. Energy Mater., 2019, 9, 1901896.

63 Y. Zheng, Y. Yi, M. Fan, H. Liu, X. Li, R. Zhang, M. Li and Z.-A. Qiao, Energy Storage Mater., 2019, 23, 678-683.

64 Y. Zhuang, L. Sun, S. Zeng, W. Zhan, X.-J. Wang, Y. Zhao and X. Han, Chem.-Eur. J., 2019, 25, 14133-14139.

65 S. Dai, Y. Bai, W. Shen, S. Zhang, H. Hu, J. Fu, X. Wang, C. Hu and M. Liu, J. Power Sources, 2021, 482, 228915.

66 W. Yang, Y. Wei, Q. Chen, S. Qin, J. Zuo, S. Tan, P. Zhai, S. Cui, H. Wang, C. Jin, J. Xiao, W. Liu, J. Shang and Y. Gong, J. Mater. Chem. A, 2020, 8, 15816-15821.

67 L. Hu, C. Dai, H. Liu, Y. Li, B. Shen, Y. Chen, S.-J. Bao and M. Xu, Adv. Energy Mater., 2018, 8, 1800709.

68 H. Lin, S. Zhang, T. Zhang, H. Ye, Q. Yao, G. W. Zheng and J. Y. Lee, Adv. Energy Mater., 2018, 8, 1801868.

69 H. Lin, L. Yang, X. Jiang, G. Li, T. Zhang, Q. Yao, G. W. Zheng and J. Y. Lee, Energy Environ. Sci., 2017, 10, 1476-1486.

70 Z. Kong, Y. Li, Y. Wang, Y. Zhang, K. Shen, X. Chu, H. Wang, J. Wang and L. Zhan, Chem. Eng. J., 2020, 392, 123697. 
71 B. Zhang, C. Luo, Y. Deng, Z. Huang, G. Zhou, W. Lv, Y.-B. He, Y. Wan, F. Kang and Q.-H. Yang, Adv. Energy Mater., 2020, 10, 2000091.

72 M. Wang, L. Fan, X. Wu, Y. Qiu, Y. Wang, N. Zhang and K. Sun, Chem.-Eur. J., 2019, 25, 5416-5421.

73 X. Li, G. Guo, N. Qin, Z. Deng, Z. Lu, D. Shen, X. Zhao, Y. Li, B.-L. Su and H.-E. Wang, Nanoscale, 2018, 10, 15505-15512.

74 Q. Fang, M. Fang, X. Liu, P. Yu, J.-C. Ren, S. Li and W. Liu, J. Mater. Chem. A, 2020, 8, 13770-13775.

75 T. Zhou, W. Lv, J. Li, G. Zhou, Y. Zhao, S. Fan, B. Liu, B. Li, F. Kang and Q.-H. Yang, Energy Environ. Sci., 2017, 10, 16941703.

76 L. Zhang, Y. Liu, Z. Zhao, P. Jiang, T. Zhang, M. Li, S. Pan, T. Tang, T. Wu, P. Liu, Y. Hou and H. Lu, ACS Nano, 2020, 14, 8495-8507.

77 Z. Jin, Z. Liang, M. Zhao, Q. Zhang, B. Liu, L. Zhang, L. Chen, L. Li and C. Wang, Chem. Eng. J., 2020, 394, 124983.

78 Z. Jin, T. Lin, H. Jia, B. Liu, Q. Zhang, L. Chen, L. Zhang, L. Li, Z. Su and C. Wang, Nanoscale, 2020, 12, 16201-16207.

79 Y. Li, T. Jiang, H. Yang, D. Lei, X. Deng, C. Hao, F. Zhang and J. Guo, Electrochim. Acta, 2020, 330, 135311.

80 C. Ye, Y. Jiao, H. Jin, A. D. Slattery, K. Davey, H. Wang and S.-Z. Qiao, Angew. Chem., Int. Ed., 2018, 57, 16703-16707.

81 W. Shen, J. Zang, H. Hu, J. Xu, Z. Zhang, R. Yan and S. Dai, Mater. Des., 2020, 195, 108992.

82 C. Y. Zhang, Z. W. Lu, Y. H. Wang, Z. Dai, H. Zhao, G. Z. Sun, W. Lan, X. J. Pan, J. Y. Zhou and E. Q. Xie, Chem. Eng. J., 2020, 392, 123734.

83 Y. Li, X. Li, Y. Hao, A. Kakimov, D. Li, Q. Sun, L. Kou, Z. Tian, L. Shao, C. Zhang, J. Zhang and X. Sun, Front. Chem., 2020, 8, 309.

84 X. Hong, Y. Liu, Y. Li, X. Wang, J. Fu and X. Wang, Polymers, 2020, 12, 331.

85 G. Chen, W. Zhong, Y. Li, Q. Deng, X. Ou, Q. Pan, X. Wang, X. Xiong, C. Yang and M. Liu, ACS Appl. Mater. Interfaces, 2019, 11, 5055-5063.

86 X. Liang, A. Garsuch and L. F. Nazar, Angew. Chem., Int. Ed., 2015, 54, 3907-3911.

87 H. Tang, W. Li, L. Pan, C. P. Cullen, Y. Liu, A. Pakdel, D. Long, J. Yang, N. McEvoy, G. S. Duesberg, V. Nicolosi and C. Zhang, Adv. Sci., 2018, 5, 1800502.

88 X. Zhang, Z. Zhang and Z. Zhou, J. Energy Chem., 2018, 27, 73-85.

89 M. Wang, Y. Song, Z. Sun, Y. Shao, C. Wei, Z. Xia, Z. Tian, Z. Liu and J. Sun, ACS Nano, 2019, 13, 13235-13243.

90 C. Ye, Y. Jiao, H. Jin, A. D. Slattery, K. Davey, H. Wang and S.-Z. Qiao, Angew. Chem., Int. Ed., 2018, 57, 16571.

91 R. Li, X. Zhou, H. Shen, M. Yang and C. Li, ACS Nano, 2019, 13, 10049-10061.

92 N. Wei, J. Cai, R. Wang, M. Wang, W. Lv, H. Ci, J. Sun and Z. Liu, Nano Energy, 2019, 66, 104190.

93 H. Ci, J. Cai, H. Ma, Z. Shi, G. Cui, M. Wang, J. Jin, N. Wei, C. Lu, W. Zhao, J. Sun and Z. Liu, ACS Nano, 2020, 14, 11929-11938.

94 Y. Dong, P. Lu, H. Shi, J. Qin, J. Chen, W. Ren, H.-M. Cheng and Z.-S. Wu, J. Energy Chem., 2019, 36, 64-73.
95 Q. Hao, G. Cui, Y. Zhang, J. Li and Z. Zhang, Chem. Eng. J., 2020, 381, 122672.

96 K. Xi, D. He, C. Harris, Y. Wang, C. Lai, H. Li, P. R. Coxon, S. Ding, C. Wang and R. V. Kumar, Adv. Sci., 2019, 6, 1800815.

97 Y. Wang, R. Zhang, J. Chen, H. Wu, S. Lu, K. Wang, H. Li, C. J. Harris, K. Xi, R. V. Kumar and S. Ding, Adv. Energy Mater., 2019, 9, 1900953.

98 H.-E. Wang, K. Yin, N. Qin, X. Zhao, F.-J. Xia, Z.-Y. Hu, G. Guo, G. Cao and W. Zhang, J. Mater. Chem. A, 2019, 7, 10346-10353.

99 H. C. Wang, C. Y. Fan, Y. P. Zheng, X. H. Zhang, W. H. Li, S. Y. Liu, H. Z. Sun, J. P. Zhang, L. N. Sun and X. L. Wu, Chem.-Eur. J., 2017, 23, 9666-9673.

100 C. Hou, Y. Hou, Y. Fan, Y. Zhai, Y. Wang, Z. Sun, R. Fan, F. Dang and J. Wang, J. Mater. Chem. A, 2018, 6, 6967-6976.

101 G. Wang, H. Wang, Y. Ling, Y. Tang, X. Yang, R. C. Fitzmorris, C. Wang, J. Z. Zhang and Y. Li, Nano Lett., 2011, 11, 3026-3033.

102 Y. Teng, X.-D. Wang, J.-F. Liao, W.-G. Li, H.-Y. Chen, Y.-J. Dong and D.-B. Kuang, Adv. Funct. Mater., 2018, 28, 1802463.

103 Y. Zhao, G. Chen, T. Bian, C. Zhou, G. I. Waterhouse, L. Z. Wu, C. H. Tung, L. J. Smith, D. O'Hare and T. Zhang, Adv. Mater., 2015, 27, 7824-7831.

104 H. Li, J. Shang, Z. Ai and L. Zhang, J. Am. Chem. Soc., 2015, 137, 6393-6399.

105 N. Tian, Z. Y. Zhou, S. G. Sun, Y. Ding and Z. L. Wang, Science, 2007, 316, 732-735.

106 L. Zhu, Y. Liu, C. Su, W. Zhou, M. Liu and Z. Shao, Angew. Chem., Int. Ed., 2016, 55, 9576-9579.

107 Q. Li, Y. Zhao, H. Liu, P. Xu, L. Yang, K. Pei, Q. Zeng, Y. Feng, P. Wang and R. Che, ACS Nano, 2019, 13, 1192111934.

108 Y. Tian, Y. Zhao, Y. Zhang, L. Ricardez-Sandoval, X. Wang and J. Li, ACS Appl. Mater. Interfaces, 2019, 11, 23271-23279.

109 Z. Li, C. Zhou, J. Hua, X. Hong, C. Sun, H. W. Li, X. Xu and L. Mai, Adv. Mater., 2020, 32, 1907444.

110 H. G. Jin, M. Wang, J. X. Wen, S. H. Han, X. J. Hong, Y. P. Cai, G. Li, J. Fan and Z. S. Chao, ACS Appl. Mater. Interfaces, 2021, 13, 3899-3910.

111 W. Xue, Z. Shi, L. Suo, C. Wang, Z. Wang, H. Wang, K. P. So, A. Maurano, D. Yu, Y. Chen, L. Qie, Z. Zhu, G. Xu, J. Kong and J. Li, Nat. Energy, 2019, 4, 374-382.

112 W. Xue, D. Yu, L. Suo, C. Wang, Z. Wang, G. Xu, X. Xiao, M. Ge, M. Ko, Y. Chen, L. Qie, Z. Zhu, A. S. Helal, W.-K. Lee and J. Li, Matter, 2019, 1, 1047-1060.

113 D. He, P. Xue, D. Song, J. Qu and C. Lai, J. Electrochem. Soc., 2017, 164, A1499-A1502.

114 J. He, C. Guo, S. Zhou, Y. Zhao, Q. Wang, S. Yang, J. Yang and Q. Wang, Inorg. Chem. Front., 2019, 6, 226-232.

115 G. Liu, D. Luo, R. Gao, Y. Hu, A. Yu and Z. Chen, Small, 2020, 16, 2001089.

116 Y. Xi, X. Ye, S. Duan, T. Li, J. Zhang, L. Jia, J. Yang, J. Wang, H. Liu and Q. Xiao, J. Mater. Chem. A, 2020, 8, 14769-14777. 
117 C. Shen, K. Zhang, Y. You, H. Wang, R. Ning, Y. Qi, N. Li, C. Ding, K. Xie and B. Wei, Nanoscale, 2020, 12, 1398013986.

118 Y. Zhang, Z. Mu, C. Yang, Z. Xu, S. Zhang, X. Zhang, Y. Li, J. Lai, Z. Sun, Y. Yang, Y. Chao, C. Li, X. Ge, W. Yang and S. Guo, Adv. Funct. Mater., 2018, 28, 1707578.

119 R. Razaq, D. Sun, J. Wang, Y. Xin, G. Abbas, J. Zhang, Q. Li, T. Huang, Z. Zhang and Y. Huang, J. Power Sources, 2019, 414, 453-459.

120 Z. Li, F. Zhang, T. Cao, L. Tang, Q. Xu, H. Liu and Y. Wang, Adv. Funct. Mater., 2020, 30, 2006297.

121 J. Zhang, J. Zhang, K. Liu, T. Yang, J. Tian, C. Wang, M. Chen and X. Wang, ACS Appl. Mater. Interfaces, 2019, 11, 46767-46775.

122 X. Li, G. Guo, N. Qin, Z. Deng, Z. Lu, D. Shen, X. Zhao, Y. Li, B. L. Su and H. E. Wang, Nanoscale, 2018, 10, 15505-15512.

123 B. Hao, H. Li, W. Lv, Y. Zhang, S. Niu, Q. Qi, S. Xiao, J. Li, F. Kang and Q.-H. Yang, Nano Energy, 2019, 60, 305-311.

124 M. Zhao, H. J. Peng, Z. W. Zhang, B. Q. Li, X. Chen, J. Xie, X. Chen, J. Y. Wei, Q. Zhang and J. Q. Huang, Angew. Chem., Int. Ed., 2019, 58, 3779-3783.

125 Y. Zhong, D. Chao, S. Deng, J. Zhan, R. Fang, Y. Xia, Y. Wang, X. Wang, X. Xia and J. Tu, Adv. Funct. Mater., 2018, 28, 1706391.

126 Y. Yi, H. Li, H. Chang, P. Yang, X. Tian, P. Liu, L. Qu, M. Li, B. Yang, H. Li, W. Zhu and S. Dai, Chem.-Eur. J., 2019, 25, 8112-8117.

127 H. Wu, H. Jiang, Y. Yang, C. Hou, H. Zhao, R. Xiao and H. Wang, J. Mater. Chem. A, 2020, 8, 14498-14505.

128 Z. Shen, Z. Zhang, M. Li, Y. Yuan, Y. Zhao, S. Zhang, C. Zhong, J. Zhu, J. Lu and H. Zhang, ACS Nano, 2020, 14, 6673-6682.

129 W. Wang, Y. Zhao, Y. Zhang, J. Wang, G. Cui, M. Li, Z. Bakenov and X. Wang, ACS Appl. Mater. Interfaces, 2020, 12, 12763-12773.

130 W. Yao, W. Zheng, K. Han and S. Xiao, J. Mater. Chem. A, 2020, 8, 19028-19042.

131 R. Wang, K. Wang, H. Tao, W. Zhao, M. Jiang, J. Yan and K. Jiang, J. Mater. Chem. A, 2020, 8, 11224-11232.

132 J. Wu, Q. Ma, C. Lian, Y. Yuan and D. Long, Chem. Eng. J., 2019, 370, 556-564.

133 J. Zhang, J. Zhang, K. Liu, T. Yang, J. Tian, C. Wang, M. Chen and X. Wang, ACS Appl. Mater. Interfaces, 2019, 11, 46767-46775.

134 J. Zhao, D. Zhao, L. Li, L. Zhou, X. Liang, Z. Wu and Z.-J. Jiang, J. Phys. Chem. C, 2020, 124, 12259-12268.

135 Z.-F. Huang, J. Song, Y. Du, S. Xi, S. Dou, J. M. V. Nsanzimana, C. Wang, Z. J. Xu and X. Wang, Nat. Energy, 2019, 4, 329-338.

136 Y. Men, P. Li, J. Zhou, G. Cheng, S. Chen and W. Luo, ACS Catal., 2019, 9, 3744-3752.

137 L. Sun, R. Li, W. Zhan, Y. Yuan, X. Wang, X. Han and Y. Zhao, Nat. Commun., 2019, 10, 2270.

138 Y. Li, L. Liu, R. Shi, S. Yang, C. Zhao, Y. Shi, C. Cao and X. Yan, Energy Technol., 2019, 7, 1900165.

139 H. Wang, W. Zhang, J. Xu and Z. Guo, Adv. Funct. Mater., 2018, 28, 1707520.
140 G. Zhou, E. Paek, G. S. Hwang and A. Manthiram, Nat. Commun., 2015, 6, 7760.

141 J. Hao, W. Zhan, L. Sun, G. Zhuang, X. Wang and X. Han, Inorg. Chem., 2020, 59, 937-942.

142 Y. Liu, Y. Yan, K. Li, Y. Yu, Q. Wang and M. Liu, Chem. Commun., 2019, 55, 1084-1087.

143 J. Tan, D. Li, Y. Liu, P. Zhang, Z. Qu, Y. Yan, H. Hu, H. Cheng, J. Zhang, M. Dong, C. Wang, J. Fan, Z. Li, Z. Guo and M. Liu, J. Mater. Chem. A, 2020, 8, 7980-7990.

144 H. Hu, H. Cheng, K. Song, S. Dai, Y. Liu, H.-R. Stock, Y. Yu, Z. Zhang and M. Liu, J. Power Sources, 2020, 472, 228599.

145 X. Liu, J. Q. Huang, Q. Zhang and L. Mai, Adv. Mater., 2017, 29, 25.

146 L. Borchardt, M. Oschatz and S. Kaskel, Chem. - Eur. J., 2016, 22, 7324-7351.

147 M. Wang, X. Xia, Y. Zhong, J. Wu, R. Xu, Z. Yao, D. Wang, W. Tang, X. Wang and J. Tu, Chem.-Eur. J., 2019, 25, 3710-3725.

148 C. Tang, Q. Zhang, M. Q. Zhao, J. Q. Huang, X. B. Cheng, G. L. Tian, H. J. Peng and F. Wei, Adv. Mater., 2014, 26, 6100-6105.

149 J. Song, T. Xu, M. L. Gordin, P. Zhu, D. Lv, Y.-B. Jiang, Y. Chen, Y. Duan and D. Wang, Adv. Funct. Mater., 2014, 24, 1243-1250.

150 H.-J. Peng, T.-Z. Hou, Q. Zhang, J.-Q. Huang, X.-B. Cheng, M.-Q. Guo, Z. Yuan, L.-Y. He and F. Wei, Adv. Mater. Interfaces, 2014, 1, 1400227.

151 J. Song, M. L. Gordin, T. Xu, S. Chen, Z. Yu, H. Sohn, J. Lu, Y. Ren, Y. Duan and D. Wang, Angew. Chem., Int. Ed., 2015, 54, 4325-4329.

152 S. S. Zhang, Inorg. Chem. Front., 2015, 2, 1059-1069.

153 Y. He, Z. Chang, S. Wu and H. Zhou, J. Mater. Chem. A, 2018, 6, 6155-6182.

154 X. Chen, Y. Xu, F. H. Du and Y. Wang, Small Methods, 2019, 3, 1900338.

155 X. Wang, T. Gao, X. Fan, F. Han, Y. Wu, Z. Zhang, J. Li and C. Wang, Adv. Funct. Mater., 2016, 26, 7164-7169.

156 J. He and A. Manthiram, Energy Storage Mater., 2019, 20, 55-70.

157 Y. Liu, S. Ma, L. Liu, J. Koch, M. Rosebrock, T. Li, F. Bettels, T. He, H. Pfnür, N. C. Bigall, A. Feldhoff, F. Ding and L. Zhang, Adv. Funct. Mater., 2020, 30, 2002462.

158 Y.-J. Li, J.-M. Fan, M.-S. Zheng and Q.-F. Dong, Energy Environ. Sci., 2016, 9, 1998-2004.

159 T. Yang, K. Liu, T. Wu, J. Zhang, X. Zheng, C. Wang and M. Chen, J. Mater. Chem. A, 2020, 8, 18032-18042.

160 H. Yuan, X. Chen, G. Zhou, W. Zhang, J. Luo, H. Huang, Y. Gan, C. Liang, Y. Xia, J. Zhang, J. Wang and X. Tao, ACS Energy Lett., 2017, 2, 1711-1719.

161 S. Z. Yang, Y. Gong, P. Manchanda, Y. Y. Zhang, G. Ye, S. Chen, L. Song, S. T. Pantelides, P. M. Ajayan, M. F. Chisholm and W. Zhou, Adv. Mater., 2018, 30, 1803477.

162 H. Lin, S. Zhang, T. Zhang, H. Ye, Q. Yao, G. W. Zheng and J. Y. Lee, Adv. Energy Mater., 2019, 9, 1902096. 
163 C. Wang, H. Xie, S. Chen, B. Ge, D. Liu, C. Wu, W. Xu, W. Chu, G. Babu, P. M. Ajayan and L. Song, Adv. Mater., 2018, 30, 1802525.

164 W. Yang, J. Xiao, Y. Ma, S. Cui, P. Zhang, P. Zhai, L. Meng, X. Wang, Y. Wei, Z. Du, B. Li, Z. Sun, S. Yang, Q. Zhang and Y. Gong, Adv. Energy Mater., 2019, 9, 1803137.

165 H. Pan, Z. Cheng, Z. Xiao, X. Li and R. Wang, Adv. Funct. Mater., 2017, 27, 1703936.

166 J. Lee, J. Oh, Y. Jeon and Y. Piao, ACS Appl. Mater. Interfaces, 2018, 10, 26485-26493.

167 P. Shi, Y. Wang, X. Liang, Y. Sun, S. Cheng, C. Chen and H. Xiang, ACS Sustainable Chem. Eng., 2018, 6, 9661-9670.

168 M. R. Kaiser, Z. Ma, X. Wang, F. Han, T. Gao, X. Fan, J. Z. Wang, H. K. Liu, S. Dou and C. Wang, ACS Nano, 2017, 11, 9048-9056.

169 P. Wang, Z. Shen, C. Xia, K. Lv, H. Zhang, P. He and H. Zhou, ACS Appl. Mater. Interfaces, 2020, 12, 47590-47598.

170 L. Du, X. Cheng, F. Gao, Y. Li, Y. Bu, Z. Zhang, Q. Wu, L. Yang, X. Wang and Z. Hu, Chem. Commun., 2019, 55, 6365-6368.

171 M. Chen, S. Zhao, S. Jiang, C. Huang, X. Wang, Z. Yang, K. Xiang and Y. Zhang, ACS Sustainable Chem. Eng., 2018, 6, 7545-7557.

172 Z. Li, F. Zhang, L. Tang, Y. Tao, H. Chen, X. Pu, Q. Xu, H. Liu, Y. Wang and Y. Xia, Chem. Eng. J., 2020, 390, 124653.

173 J. Ren, Y. Zhou, L. Xia, Q. Zheng, J. Liao, E. Long, F. Xie, C. Xu and D. Lin, J. Mater. Chem. A, 2018, 6, 13835-13847.

174 B. P. Vinayan, T. Diemant, X.-M. Lin, M. A. Cambaz, U. Golla-Schindler, U. Kaiser, R. Jürgen Behm and M. Fichtner, Adv. Mater. Interfaces, 2016, 3, 1600372.

175 Y. Chen, W. Zhang, D. Zhou, H. Tian, D. Su, C. Wang, D. Stockdale, F. Kang, B. Li and G. Wang, ACS Nano, 2019, 13, 4731-4741.

176 S. Liu, J. Li, X. Yan, Q. Su, Y. Lu, J. Qiu, Z. Wang, X. Lin, J. Huang, R. Liu, B. Zheng, L. Chen, R. Fu and D. Wu, Adv. Mater., 2018, 30, 1706895.

177 Y. Wang, D. Adekoya, J. Sun, T. Tang, H. Qiu, L. Xu, S. Zhang and Y. Hou, Adv. Funct. Mater., 2018, 29, 1807485.

178 W. Zang, Z. Kou, S. J. Pennycook and J. Wang, Adv. Energy Mater., 2020, 10, 1903181.

179 C. Lu, R. Fang and X. Chen, Adv. Mater., 2020, 32, 1906548. 180 Q. Shao, L. Xu, D. Guo, Y. Su and J. Chen, J. Mater. Chem. A, 2020, 8, 23772-23783.

181 M. B. Gawande, P. Fornasiero and R. Zbořil, ACS Catal., 2020, 10, 2231-2259.

182 Y. Li, S. Lin, D. Wang, T. Gao, J. Song, P. Zhou, Z. Xu, Z. Yang, N. Xiao and S. Guo, Adv. Mater., 2020, 32, 1906722.

183 J. Gu, Q. Zhu, Y. Shi, H. Chen, D. Zhang, Z. Du and S. Yang, ACS Nano, 2020, 14, 891-898.

184 Y. Li, P. Zhou, H. Li, T. Gao, L. Zhou, Y. Zhang, N. Xiao, Z. Xia, L. Wang, Q. Zhang, L. Gu and S. Guo, Small Methods, 2020, 4, 1900701.
185 Z. Du, X. Chen, W. Hu, C. Chuang, S. Xie, A. Hu, W. Yan, X. Kong, X. Wu, H. Ji and L.-J. Wan, J. Am. Chem. Soc., 2019, 141, 3977-3985.

186 Y. Li, J. Wu, B. Zhang, W. Wang, G. Zhang, Z. W. Seh, N. Zhang, J. Sun, L. Huang, J. Jiang, J. Zhou and Y. Sun, Energy Storage Mater., 2020, 30, 250-259.

187 L. Zhang, D. Liu, Z. Muhammad, F. Wan, W. Xie, Y. Wang, L. Song, Z. Niu and J. Chen, Adv. Mater., 2019, 31, 1903955.

188 C. Wang, H. Song, C. Yu, Z. Ullah, Z. Guan, R. Chu, Y. Zhang, L. Zhao, Q. Li and L. Liu, J. Mater. Chem. A, 2020, 8, 3421-3430.

189 H. Zhao, B. Tian, C. Su and Y. Li, ACS Appl. Mater. Interfaces, 2021, 13, 7171-7177.

190 C. Sun, C. Wu, X. Gu, C. Wang and Q. Wang, Nano-Micro Lett., 2021, 13, 89.

191 D. Zhang, S. Wang, R. Hu, J. Gu, Y. Cui, B. Li, W. Chen, C. Liu, J. Shang and S. Yang, Adv. Funct. Mater., 2020, 30, 2002471.

192 C. Lu, Y. Chen, Y. Yang and X. Chen, Nano Lett., 2020, 20, 5522-5530.

193 Z. Liu, L. Zhou, Q. Ge, R. Chen, M. Ni, W. Utetiwabo, X. Zhang and W. Yang, ACS Appl. Mater. Interfaces, 2018, 10, 19311-19317.

194 G. Cao, Z. Wang, D. Bi, J. Zheng, Q. Lai and Y. Liang, Chem. Eur. J., 2020, 26, 10314-10320.

195 J. Wang, L. Jia, J. Zhong, Q. Xiao, C. Wang, K. Zang, H. Liu, H. Zheng, J. Luo, J. Yang, H. Fan, W. Duan, Y. Wu, H. Lin and Y. Zhang, Energy Storage Mater., 2019, 18, 246-252.

196 K. Zhang, Z. Chen, R. Ning, S. Xi, W. Tang, Y. Du, C. Liu, Z. Ren, X. Chi, M. Bai, C. Shen, X. Li, X. Wang, X. Zhao, K. Leng, S. J. Pennycook, H. Li, H. Xu, K. P. Loh and K. Xie, ACS Appl. Mater. Interfaces, 2019, 11, 25147-25154.

197 J. Wu, J. Chen, Y. Huang, K. Feng, J. Deng, W. Huang, Y. Wu, J. Zhong and Y. Li, Sci. Bull., 2019, 64, 1875-1880.

198 J. Wang, L. Jia, S. Duan, H. Liu, Q. Xiao, T. Li, H. Fan, K. Feng, J. Yang, Q. Wang, M. Liu, J. Zhong, W. Duan, H. Lin and Y. Zhang, Energy Storage Mater., 2020, 28, 375382.

199 C. Zhao, G.-L. Xu, Z. Yu, L. Zhang, I. Hwang, Y.-X. Mo, Y. Ren, L. Cheng, C.-J. Sun, Y. Ren, X. Zuo, J.-T. Li, S.-G. Sun, K. Amine and T. Zhao, Nat. Nanotechnol., 2021, 16, 166-173.

200 H. Shi, X. Ren, J. Lu, C. Dong, J. Liu, Q. Yang, J. Chen and Z.-S. Wu, Adv. Energy Mater., 2020, 10, 2002271.

201 Y. Liu, Z. Wei, B. Zhong, H. Wang, L. Xia, T. Zhang, X. Duan, D. Jia, Y. Zhou and X. Huang, Energy Storage Mater., 2021, 35, 12-18.

202 W. Xue, L. Miao, L. Qie, C. Wang, S. Li, J. Wang and J. Li, Curr. Opin. Electrochem., 2017, 6, 92-99.

203 M. Hagen, D. Hanselmann, K. Ahlbrecht, R. Maça, D. Gerber and J. Tübke, Adv. Energy Mater., 2015, 5, 1401986. 